\title{
Functional Molecular System of Bis(pyrazolyl)pyridine Derivatives: Photophysics, Spectroscopy, Computation, and Ion Sensing
}

\author{
Indravath K. Naik, Ramakrishna Bodapati, Rudraditya Sarkar, ${ }^{\circledR}$ Navendu Mondal, ${ }^{\circledR}$ and Samar K. Das*(i) \\ School of Chemistry, University of Hyderabad, Hyderabad 500 046, India
}

Supporting Information

\begin{abstract}
A new series of conjugated donor- $\pi$-acceptor type of 2,6-bis(pyrazolyl)pyridine derivatives (compounds IK-(3-9)) have been synthesized via Horner-WadsworthEmmons (HWE) reaction, starting from a common phosphonate precursor and diverse donor aromatic aldehydes and characterized by routine spectral analysis including elemental analysis. Compound IK-2, one of the starting precursors, and molecule IK-3, the first member of the donor $-\pi$-acceptor series, are additionally characterized by single-crystal X-ray structure determination. Compounds IK-2 and IK-3 are crystallized in $P \overline{1}$ (triclinic) and $P 2_{1} / c$ (monoclinic) space groups, respectively. The absorption maxima in the electronic spectra of the title compounds shift mainly due to intramolecular charge transfer (ICT) between different donor (dibutyl and cyclic pyrrolidine) groups and the acceptor moiety [2,6bis(pyrazolyl) pyridine]. Solution-state emission spectral studies of all these compounds show large solvent sensitive behavior with significant amounts of Stokes shifts. The large solvent dependence of the emission indicates that the excited state is stabilized in more polar solvents due to the ICT. All chromophores exhibit solid-state fluorescence behavior except compound

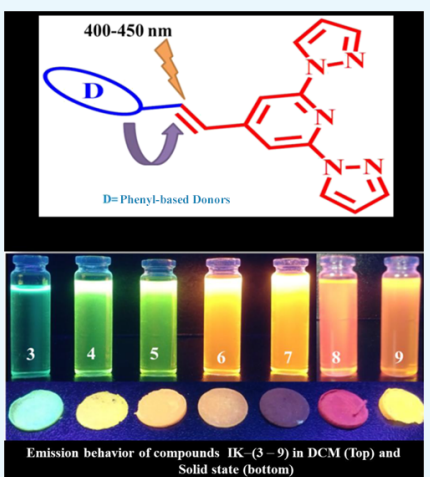
IK-7. The role of the position and nature of the donor functionalities in the conjugated backbone of overall donor moiety of compounds IK-(3-9), on the electronic absorption properties of the title chromophores has been demonstrated, which has further been corroborated by density functional theory (DFT) and time-dependent DFT (TDDFT) computational studies. The emission spectral results of compounds IK-3, IK-5, and IK-7 have also been supported by the DFT and TDDFT calculations. A fluorescence lifetime study on this series also shows that the excited states are stabilized in more polar solvents. Finally, one of the chromophores (chromophore IK-4) in the title series has been shown to act as a selective molecular sensor (turn-off switch) for the $\mathrm{Cu}(\mathrm{II})$ ion.
\end{abstract}

\section{INTRODUCTION}

Fluorescence $^{1-4}$ has turned out to be an essential analytical technique in various branches of science, most importantly, in the fields of analytical, biological, and medicinal sciences. Among the various classes of emissive organic $\pi$-systems, materials that absorb electromagnetic radiation by virtue of an intramolecular charge transfer (ICT) and emit from the corresponding photoexcited state are the most interesting ones because of their prominent applications in the fields of molecular electronics, integrated photonic devices, nonlinear optics, and so forth. ${ }^{5-7}$ The well-designed electron donor and acceptor (DA) or "push-pull" architecture can be fabricated via the electronic association between the donor and acceptor mesomeric units in a chromophore system, which, in turn, is linked with diverse functionalities for spontaneous charge redistribution. Particularly, $\pi$-conjugated chromophores with donor and acceptor moieties are of considerable interest in terms of tuning their optical properties wisely, over a wide range simply by varying the donor or acceptor moieties. During the last three decades, the dynamics of ICT in the excited states of various aromatic molecules of the type $\mathrm{D}-\mathrm{Ar}-\mathrm{A}$ (where $\mathrm{Ar}$ is an aromatic system linking $\mathrm{D}$ and $\mathrm{A}$ through $\pi$ conjugation) have been the subject of extensive theoretical and experimental investigations. $^{8-13}$ The most fundamental types of interaction in such D-A systems generally occur by virtue of ICT between the donor (D) and the acceptor (A), thereby tuning the highest occupied molecular orbital (HOMO)-lowest unoccupied molecular orbital (LUMO) energy gap. The singlet state undergoes preferable stabilization in more polar solvents via solvent reorganization, which can be realized by large Stokes shifts of the fluorescence emission. ${ }^{14-18}$ Numerous $\pi$ conjugated systems that can be described as functional materials are particularly important to the development of organic light-emitting diodes, ${ }^{19}$ electrogenerated chemiluminescence, $^{20}$ dye-sensitized solar cells, ${ }^{21}$ and fluorescent sensors. $^{22-25}$ Some years ago, we have established a series of $4,4^{\prime}-\pi$-conjugated-2,2'-bipyridine chromophores and investigated their photophysical and thermal properties. ${ }^{26}$ We have also reported a series of asymmetrically substituted and $\pi$ conjugated 2,2'-bipyridine derivatives including their photophysics and computational studies. ${ }^{27}$ Last several years, in our laboratory, we have been exploring diverse inorganic and organic systems that can be described as functional materials. $^{28-30}$ As a part of our recent research on exploring

Received: December 17, 2017

Accepted: February 20, 2018

Published: March 13, 2018 
Chart 1. Molecules Synthesized and Studied in the Present Work

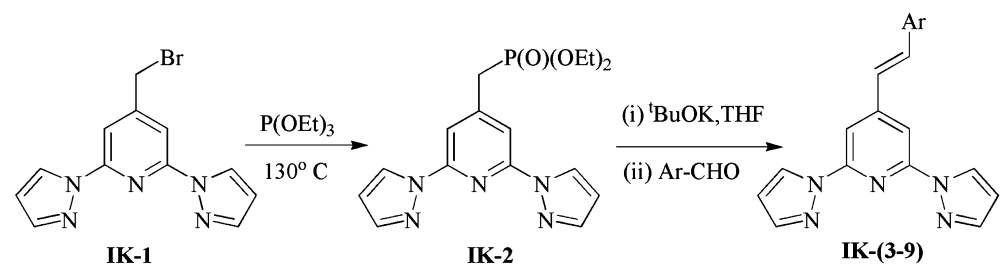

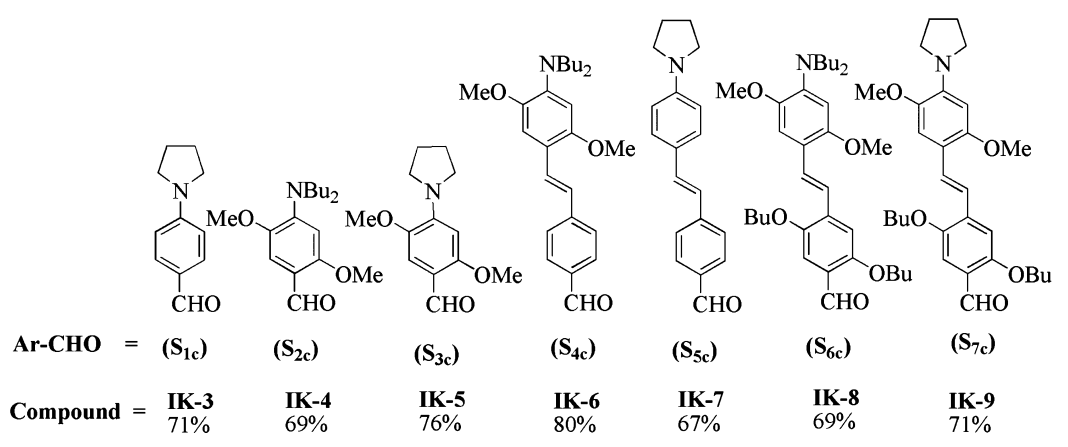

(a)

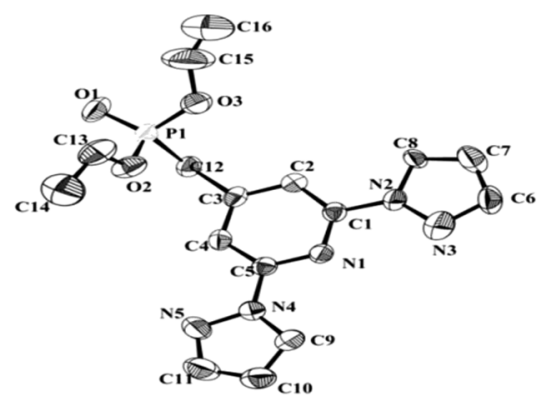

(b)

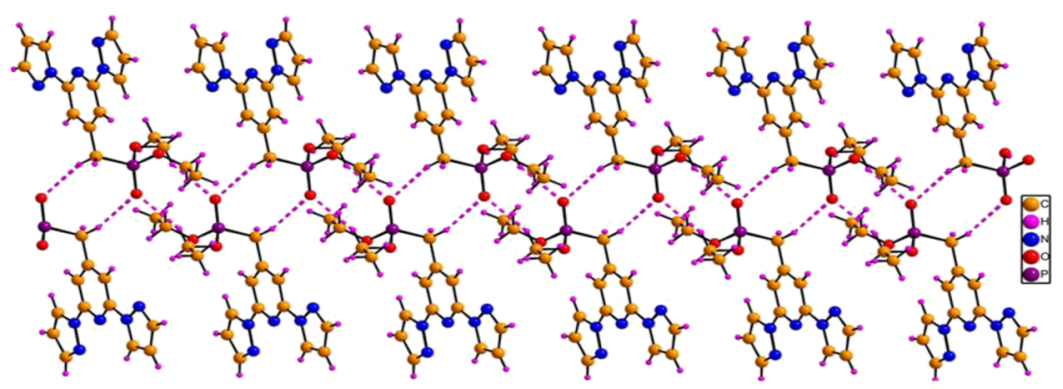

Figure 1. (a) Thermal ellipsoidal plot of compound IK-2 (50\% probability); hydrogens are omitted for clarity. (b) View of the chainlike structure, observed in the crystal structure of compound IK-2, observed by the $\mathrm{C}-\mathrm{H} \cdots \mathrm{O}(2.55 \AA)$ weak hydrogen-bonding interactions.

functional materials, we have recently developed interests in fluorescent chemosensors and reported our first success in selective sensing of $\mathrm{Fe}^{3+}$ ion and $\mathrm{IO}_{4}^{-}$ion by a metallocycle host. ${ }^{31}$ Fluorescent sensing has received great attention because of its simple operation, high selectivity, and sensitivity. The metal-selective fluorescent chemosensors are widely exploited to detect biologically or environmentally relevant metal ions. A $\mathrm{Cu}^{2+}$ ion is a biologically as well as magnetically active metal ion, which is potentially important to be detected by a fluorescent sensor. ${ }^{32-34}$ The strong fluorescence quenching for most of the luminescent sensors for the $\mathrm{Cu}$ (II) ion is due to the fast electron and energy transfer involving paramagnetic copper center. $^{35-39}$ In this work, we have chosen a $\pi$-conjugated trisheterocyclic ligand system, namely, 2,6-bis(pyrazolyl)pyridine derivatives, because such tris-heterocyclic ligands are important in recent years not only because of their synthetic flexibility, strong metal binding tendency, and spin crossover properties of their iron complexes but also because of their potential to act as a fluorescent sensor for a metal ion because of their strong luminescence behavior. 2,6-Bis(pyrazolyl)pyridine derivatives have recently been exploited in diverse areas including catalysis, solar cell photosensitization, magnetism, and so forth. ${ }^{40-45}$

We wish to report, in this article, the synthesis and characterization of $\pi$-conjugated donor-acceptor molecules (compounds IK-(3-9), Chart 1) containing 2,6-bis(pyrazolyl)pyridine core as a common acceptor moiety and diverse donor moieties (second row, Chart 1). The chromophores, IK-(3-9) (Chart 1), were found to display bright fluorescence in the solution, and compounds (IK-(3-6), IK-8, and IK-9) exhibit solid-state fluorescence at room temperature. We have demonstrated that one of the title chromophore (compound IK-4) acts as a fluorescence probe for the selective sensing of the $\mathrm{Cu}^{2+}$ ion. We have also performed density functional theory (DFT) calculations to corroborate the UV-visible and 

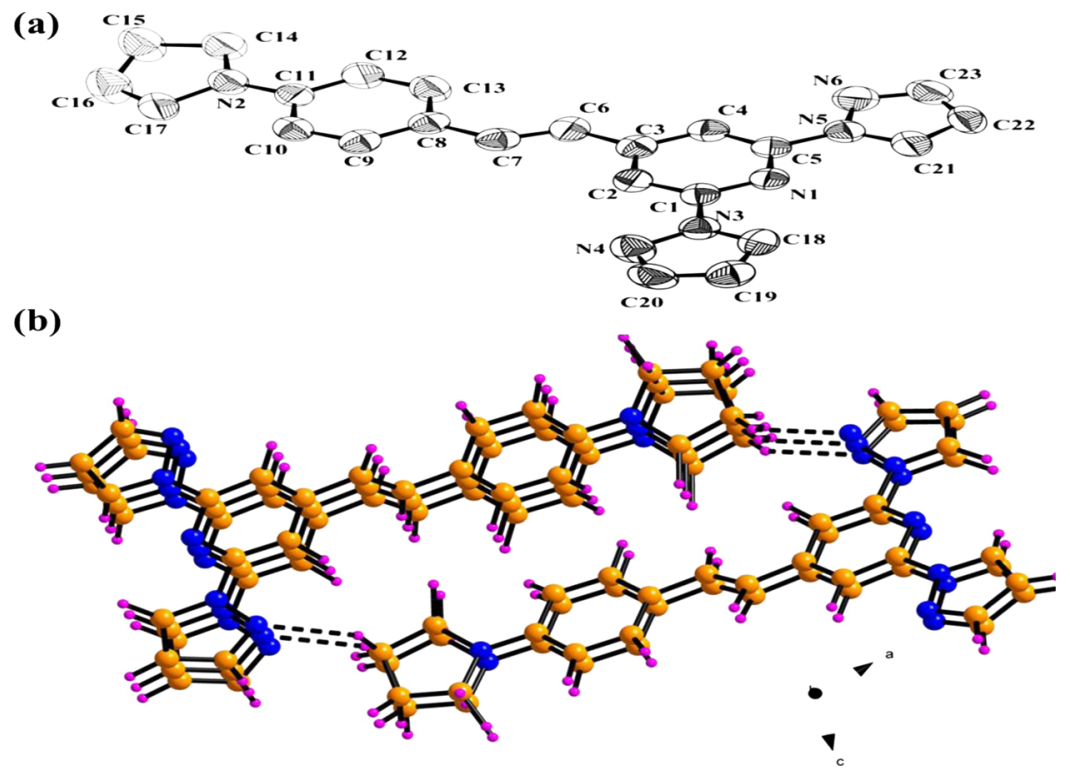

Figure 2. (a) Thermal ellipsoidal plot of compound IK-3 (30\% probability); hydrogens are omitted for clarity. (b) Supramolecular C-H $\cdots \mathrm{N}$ (2.684 $\AA$ ) hydrogen-bonding and $\pi-\pi$ stacking interactions, observed in the crystal structure of compound IK-3; color code: C, yellow; N, blue; and H, pink.

Table 1. Crystallographic Data and Structure Refinement for Compounds IK-2 and IK-3

\begin{tabular}{|c|c|c|}
\hline & compound IK-2 & compound IK-3 \\
\hline empirical formula & $\mathrm{C}_{16} \mathrm{H}_{20} \mathrm{~N}_{5} \mathrm{O}_{3} \mathrm{P}$ & $\mathrm{C}_{23} \mathrm{H}_{22} \mathrm{~N}_{6}$ \\
\hline formula weight & 361.34 & 382.47 \\
\hline temperature $(\mathrm{K})$ & $293(2) \mathrm{K}$ & $273(2) \mathrm{K}$ \\
\hline crystal size $(\mathrm{mm})$ & $0.12 \times 0.11 \times 0.10$ & $0.21 \times 0.17 \times 0.14$ \\
\hline crystal system & triclinic & monoclinic \\
\hline space group & $P \overline{1}$ & $P 2_{1} / \mathrm{c}$ \\
\hline Z & 2 & 4 \\
\hline wavelength $(\AA)$ & 0.71073 & 0.71073 \\
\hline \multicolumn{3}{|l|}{ unit cell dimensions } \\
\hline$a(\AA)$ & $7.4514(7)$ & $24.483(2)$ \\
\hline$b(\AA)$ & $10.2478(9)$ & $4.4738(4)$ \\
\hline$c(\AA)$ & $12.0251(10)$ & $19.705(2)$ \\
\hline$\alpha\left(^{\circ}\right)$ & $74.076(2)$ & 90 \\
\hline$\beta\left(^{\circ}\right)$ & $89.7640(2)$ & 113.73 \\
\hline$\gamma\left({ }^{\circ}\right)$ & $85.604(2)$ & 90 \\
\hline volume $\left(\AA^{3}\right)$ & $880.27(13)$ & $1975.9(3)$ \\
\hline calculated density $\left(\mathrm{mg} / \mathrm{m}^{3}\right)$ & 1.363 & 1.286 \\
\hline reflections collected/unique & $30590 / 3943$ & $9935 / 3218$ \\
\hline$R$ (int) & 0.0770 & 0.1081 \\
\hline$F(000)$ & 380 & 808 \\
\hline max. and min. transmission & 0.982 and 0.978 & 0.415 and 0.398 \\
\hline theta range for data collection ( $\mathrm{deg}$ ) & $2.74-27.27$ & $3.42-26.36$ \\
\hline refinement method & full-matrix least-squares on $F^{2}$ & full-matrix least-squares on $F^{2}$ \\
\hline data/restrains/parameters & $3943 / 1 / 226$ & $3218 / 0 / 262$ \\
\hline goodness-of-fit on $F^{2}$ & 1.034 & 0.869 \\
\hline$R_{1} / \mathrm{w} R_{2}[I>2 \sigma(I)]$ & $0.0852 / 0.2203$ & $0.0852 / 0.2269$ \\
\hline$R_{1} / \mathrm{w} R_{2}$ (all data) & $0.1225 / 0.2550$ & $0.2181 / 0.3066$ \\
\hline largest diff. peak and hole & 1.229 and -0.675 e $\AA^{-3}$ & 0.143 and -0.151 e $\AA^{-3}$ \\
\hline
\end{tabular}

emission spectral results of the title donor $-\pi$-acceptor chromophores.

\section{RESULTS AND DISCUSSION}

Synthesis. The 2,6-bis(pyrazolyl)-4-bromomethyl pyridine precursor IK-1 (see Chart 1 for the structural representation of IK-1 $)^{46}$ and the required appropriate $\mathrm{N}, \mathrm{N}$-dialkylated- and pyrrolidine-substituted aldehydes $\boldsymbol{S}_{1 \mathrm{c}-7 \mathrm{c}}{ }^{26,27}$ (see Scheme $\mathrm{S} 1$, Supporting Information for syntheses and structural drawings of $S_{1 c-7 c}$ ) along with their precursors were synthesized according to the literature procedures in good yields (see Schemes $S 1$ and $S 2$ in the Supporting Information). Compound IK-2 (phosphate derivative, see Chart 1) was synthesized by Arbuzov reaction of compound IK-1 with 


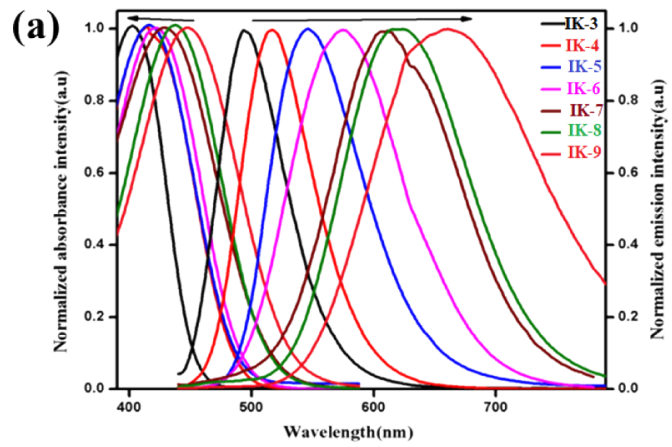

(b)
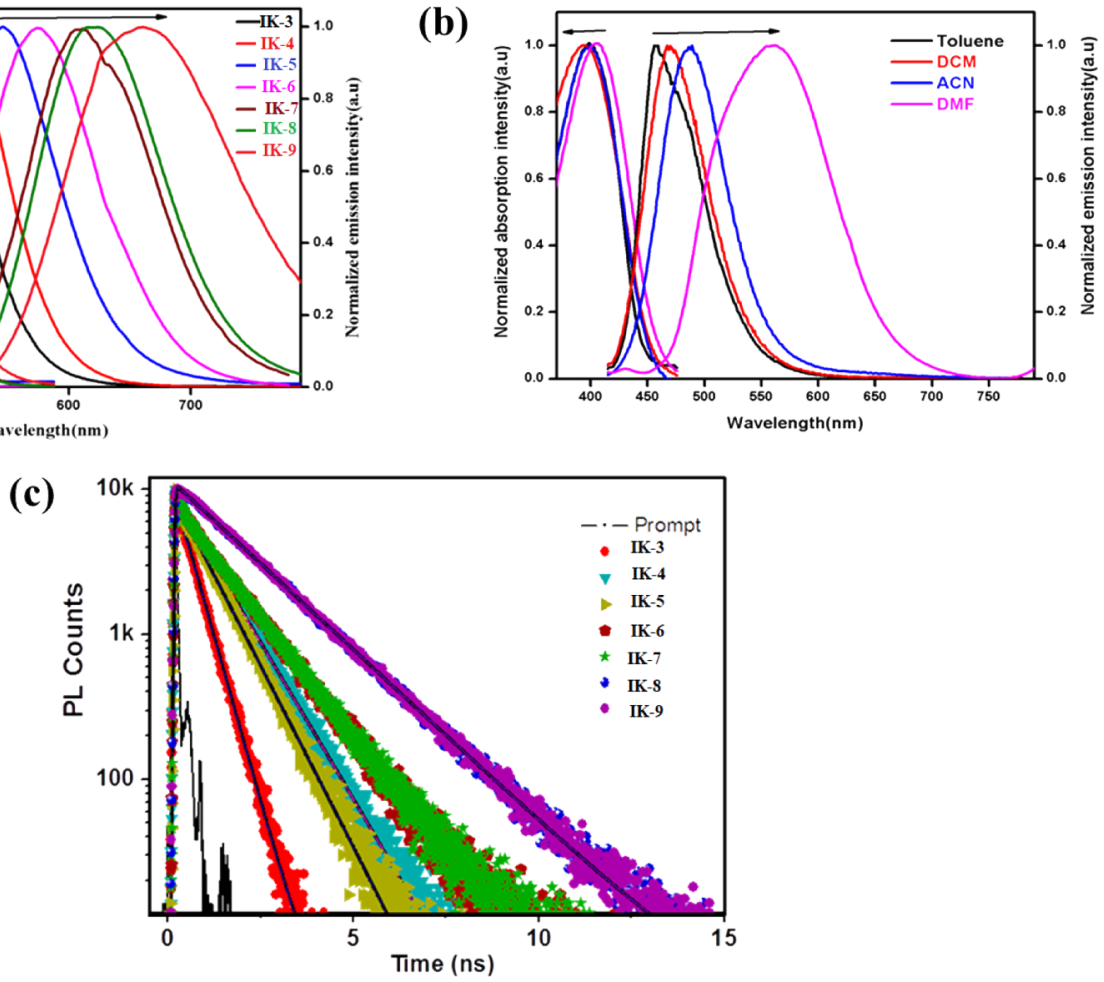

Figure 3. (a) Normalized UV-vis absorption and PL spectra of compounds IK-(3-9) in the DCM solvent. (b) Normalized UV-vis absorption and PL spectra of compound IK-3 showing the solvatochromic effect. (c) Fluorescence decay traces of compounds IK-(3-7) were measured in the MeCN medium and those of compounds IK-8 and IK-9 were measured in the toluene medium.

triethyl phosphite. The target molecules (compounds IK-(39)) have been synthesized using an efficient HornerWadsworth-Emmons (HWE) reaction pathway (Chart 1). The advantages of the HWE reaction pathway over the conventional Wittig reaction are of many folds: (i) the former one has a good response with the stabilized yields, (ii) it mainly gives E-stereo selectivity of the olefin bond, and (iii) it generates a water-soluble phosphate which can easily be removed from the reaction mixture through the aqueous process. The difficulty over the separation of Wittig by-product, triphenylphosphine oxide is thus largely ruled out in the HWE reaction.

After purification by column chromatography was done, the molecular structures of all chromophores IK-(3-9) were determined by infrared (IR), NMR $\left({ }^{1} \mathrm{H}\right.$ and $\left.{ }^{13} \mathrm{C}\right)$, and mass spectral studies including $\mathrm{CHN}$ analyses (for characterization data, see Supporting Information, Figures S7-S34).

Crystal Structure Description and Discussion. Compound IK-2 crystallizes in the triclinic system with space group $P \overline{1}$. The thermal ellipsoidal plot of the crystal structure of compound IK-2 is displayed in Figure 1a. In the crystal structure, the concerned molecule undergoes $\mathrm{C}-\mathrm{H} \cdots \mathrm{O}(2.55$ $\AA$ ) intramolecular hydrogen-bonding interactions, leading to a chainlike supramolecular arrangement (Figure 1b). Compound IK-3 crystallizes in the monoclinic system with space group $P 2_{1} / c$. The X-ray analysis of a single crystal of compound IK-3 reveals that the concerned asymmetric unit consists of the full molecule, and the thermal ellipsoidal plot of the same is presented in Figure 2a. The crystal data and structure refinement parameters of compounds IK-2 and IK-3 are given in Table 1. Interestingly, in the crystal structure of compound IK-3, the molecules undergo $\mathrm{C}-\mathrm{H} \cdots \mathrm{N}(2.68 \AA$ ) intermolecular hydrogen-bonding interactions, leading to a supramolecular dimer structure (Figure $2 \mathrm{~b}$ ). In the case of compound IK-3, both intermolecular hydrogen-bonding and $\pi-\pi$ stacking interactions play a vital role in the supramolecular ordering, which leads to the formation a pseudo-sheetlike structure, as shown in Figure $2 \mathrm{~b}$. The bond lengths and bond angles, observed in the crystal structures of compounds IK-2 and IK-3, are presented in the section of the Supporting Information (Tables S3 and S4 for compound IK-2 and Tables S7 and S8 for compound IK-3). The sheetlike structure, formed from the multilayered supramolecular aggregates via intramolecular $\pi-\pi$ stacking interactions $(d=4.474 \AA$ ) of the associated pyridine rings (J-aggregation), justifies the bathochromic shift in the absorption maxima in going from the solution to solid state (vide infra).

Photophysical Studies. The absorption and emission spectra of the title compounds were recorded in different solvents at room temperature $(298 \pm 2 \mathrm{~K})$. Figure 3a displays normalized UV-vis absorption and photoluminescence (PL) spectra of compounds IK-(3-9) in a dichloromethane (DCM) solvent. The absorption spectra of all of the title compounds exhibit a broad absorption band in the visible region $\left(\lambda_{\max }=\right.$ 400-495 nm). These absorption bands are assigned to the intraligand charge-transfer bands which are originated due to charge delocalization from the donor dialkyl (compounds IK-4, IK-6, and IK-8) or pyrrolidine (compounds IK-3, IK-5, IK-7, and IK-9) amino group to (2,6-bis(pyrazolyl)pyridine) acceptor subunits through the $\pi$-transmitters in the "push-pull" molecules. In all of the cases, the single band is well-resolved in this region, which has been confirmed due to its sensitivity to solvent polarity. Figure $3 \mathrm{~b}$ depicts the spectra recorded in four different solvents, viz., toluene, DCM, acetonitrile $(\mathrm{MeCN})$, and dimethylformamide (DMF), at room temperature, and the corresponding optical data are summarized in Table 2. From 
Table 2. Photophysical Data of All of the $D-\pi-A$ Compounds IK-(3-9)

\begin{tabular}{|c|c|c|c|c|c|c|}
\hline $\begin{array}{l}\text { compound } \\
\text { IK- }\end{array}$ & solvent & $\begin{array}{l}\lambda_{\max } \\
(\mathrm{nm})\end{array}$ & $\left(\mathrm{M}^{-1} \mathrm{~cm}^{a} \mathrm{~cm}^{-1}\right)$ & $\begin{array}{c}\lambda_{\mathrm{em}} \\
(\mathrm{nm})\end{array}$ & $\begin{array}{c}\Phi_{\mathrm{em}}^{b} \\
(\%)\end{array}$ & $\begin{array}{c}\Delta \bar{\nu}^{c} \\
\left(\mathrm{~cm}^{-1}\right)\end{array}$ \\
\hline \multirow[t]{4}{*}{3} & toluene & 398 & 39473 & 460 & 21.5 & 3836 \\
\hline & $\mathrm{DCM}$ & 391 & 28947 & 493 & 30.73 & 5292 \\
\hline & $\mathrm{MeCN}$ & 399 & 34210 & 507 & 58.96 & 5339 \\
\hline & DMF & 405 & 44736 & 562 & 81.66 & 6898 \\
\hline \multirow[t]{4}{*}{4} & toluene & 402 & 26000 & 490 & 78.34 & 4467 \\
\hline & DCM & 403 & 14000 & 521 & 74.14 & 5620 \\
\hline & $\mathrm{MeCN}$ & 404 & 26000 & 537 & 38.37 & 6131 \\
\hline & DMF & 412 & 16000 & 559 & 54.72 & 6382 \\
\hline \multirow[t]{4}{*}{5} & toluene & 417 & 11363 & 492 & 31.08 & 3655 \\
\hline & DCM & 419 & 20361 & 527 & 27.96 & 4891 \\
\hline & $\mathrm{MeCN}$ & 413 & 25000 & 548 & 50.33 & 5965 \\
\hline & DMF & 426 & 27272 & 590 & 53.18 & 6525 \\
\hline \multirow[t]{4}{*}{6} & toluene & 415 & 20000 & 635 & 32.52 & 8348 \\
\hline & DCM & 422 & 8333 & 627 & 46.83 & 7748 \\
\hline & $\mathrm{MeCN}$ & 413 & 20000 & 650 & 62.64 & 8829 \\
\hline & DMF & 421 & 26666 & 722 & 85.92 & 9902 \\
\hline \multirow[t]{4}{*}{7} & toluene & 424 & 20833 & 621 & 26.69 & 7481 \\
\hline & DCM & 424 & 27083 & 618 & 38.42 & 7403 \\
\hline & $\mathrm{MeCN}$ & 413 & & 674 & 45.16 & 9377 \\
\hline & DMF & 419 & 25000 & 714 & 56.48 & 9861 \\
\hline \multirow[t]{4}{*}{8} & toluene & 437 & 10723 & 635 & 34.82 & 7135 \\
\hline & DCM & 436 & 17426 & 659 & 45.25 & 7761 \\
\hline & $\mathrm{MeCN}$ & 433 & & 702 & 16.36 & 8849 \\
\hline & DMF & 442 & 14745 & 723 & 67.78 & 8843 \\
\hline \multirow[t]{4}{*}{9} & toluene & 449 & 10294 & 635 & 34.81 & 6523 \\
\hline & DCM & 446 & 11764 & 676 & 46.16 & 7624 \\
\hline & $\mathrm{MeCN}$ & 442 & & 712 & 18.92 & 8580 \\
\hline & DMF & 451 & 8823 & 723 & 76.78 & 8341 \\
\hline
\end{tabular}

${ }^{a} \varepsilon$ was measured in toluene, DCM, MeCN, and DMF solution, but the case where no data are reported is due to low solubility. ${ }^{b}$ Fluorescence relative quantum yield of compounds IK-(3-9) was measured by using fluorescein (in $0.1 \mathrm{~N} \mathrm{NaOH}$ in $\mathrm{EtOH})$ as the reference $\left(\Phi_{\mathrm{em}}=\right.$ 0.79). ${ }^{c}$ Stokes shift $\Delta \bar{\nu}=\bar{\nu}_{\mathrm{abs}}-\bar{\nu}_{\mathrm{em}}$.

the absorption spectra, it is quite evident that the compounds with pyrrolidine donors (for example, IK-5 and IK-9) exhibit a bathochromic shift by $\approx 10 \mathrm{~nm}$ compared to the compounds with corresponding dibutyl amino group-substituted donors (IK-4 and IK-8). The cyclic pyrrolidine ring-substituted donor has a more donating capability compared to the open-chain dibutyl amino donor (consistent with NMR spectroscopy; see relevant section of the Supporting Information; Figure S35). PL has been observed for all of the title chromophores IK-(3-9) at room temperature $(298 \pm 2 \mathrm{~K})$. All solutions have been excited at their respective lowest energy absorption maxima, and in all cases, they exhibit excellent fluorescence behavior in various solvents (Figure 3a,b). The obtained photophysical data in various solvents and fluorescence lifetime studies suggest that the excited states of all of the title compounds IK-(3-9) are more polar than their respective ground states. On varying the solvent polarity from lower (toluene solvent) to higher (DMF solvent), the shifts in emission bands were found to be more profound than those in the corresponding absorption bands. Generally, the dipole character is increased in the excited state $S_{1}$, when the electrons are excited from the HOMO to the LUMO. As a result, the solvents with high polarity tend to stabilize such a polarized excited state by reorienting the solvent molecules so as to lower the energy of the system, thereby leading to a red shift in the emission spectra. This is well- explained from DFT calculations and their molecular orbital (MO) diagrams (vide infra) and fluorescence lifetime studies (see Figure 3c). The entire series of compounds IK-(3-9) exhibits strong emission in the solution (see Figures S36-S38, Supporting Information) as well as in the solid state (except compound IK-7) at room temperature, as shown in Figure S39 Supporting Information. Thus, the emission spectra of compounds IK-(3-9) are strongly dependent on the polarity of the solvent [see Tables 2 and S9 (Supporting Information)]. The emission of the compound IK-3 varies from green to red with increasing polarity of the solvent, for example, in the solution of moderate polar solvent, such as toluene, it shows blue emission and the emission maximum is centered at 460 $\mathrm{nm}$, as shown in Figure $3 \mathrm{~b}$. On the other hand, in the solution of more polar solvent, such as DMF, this shows green emission and the pertinent emission maximum centers at $562 \mathrm{~nm}$, as shown in Figure $3 \mathrm{~b}$. Hence, the solvent dependence of the emission shows that the excited state is stabilized in more polar solvents, which is due to an ICT. It has also been observed that on increasing the conjugation length in this series of compounds, the absorption and emission maxima are bathochromically shifted, as shown in Figure 3a. For example, when we compared the absorption and emission of compounds IK-3 versus IK-7 or IK-4 versus IK-6 in DCM, it has been observed that the $\lambda_{\mathrm{abs}}$ and $\lambda_{\mathrm{em}}$ values increase with increasing the conjugation length (Table 2). Comparison between the chromophores, based on the nature and position of the donor functionalities, gives us some insight into the photophysical properties. In cyclic donor systems (for example, compounds IK-5 and IK-9) the absorption and emission bands in the chromophores are red shifted with good quantum yields compared to their corresponding acyclic donor systems (compounds IK-4 and IK-8).

The fluorescence lifetime of the entire series of compounds IK-(3-9) (see Figure 3c) was measured through the timecorrelated single photon counting technique by monitoring their respective emission maximum using a picosecond laser diode of $375 \mathrm{~nm}$ as an excitation source. Fluorescence decay traces of all title compounds are best fitted using a biexponential decay function $I(t)=a_{1} \times \exp \left(-t / \tau_{1}\right)+a_{2} \times$ $\exp \left(-t / \tau_{2}\right)$, where $\tau_{1}$ and $\tau_{2}$ are the lifetime components and $a_{1}$ and $a_{2}$ are their respective amplitudes. Among all these derivatives, compound IK-3 in $\mathrm{MeCN}$ shows a shorter lifetime with the shortest component ( $<65 \mathrm{ps,} \mathrm{IRF)} \mathrm{having} \mathrm{a} \mathrm{minor}$ amplitude and a major component of $0.47 \mathrm{ns,} \mathrm{whereas}$ chromophores IK-8 and IK-9 show longest lifetime (1.83 $\mathrm{ns})$, as shown in Table 3.

Table 3. Radiative $\left(k_{\mathrm{r}}\right)$ and Nonradiative $\left(k_{\mathrm{nr}}\right)$ Rate Constant $^{a}$ for Compounds IK-(3-9)

$\begin{array}{ccccc}\text { sample IK- } & \tau_{1}\left(a_{1}\right)(\mathrm{ps}) & \tau_{2}\left(a_{2}\right)(\mathrm{ns}) & k_{\mathrm{r}}\left(10^{7} \mathrm{~S}^{-1}\right) & k_{\mathrm{nr}}\left(10^{9} \mathrm{~S}^{-1}\right) \\ \mathbf{3} & <65(0.16) & 0.47(0.84) & 1.25 & 0.87 \\ \mathbf{4} & <65(0.07) & 1.01(0.93) & 0.38 & 0.62 \\ \mathbf{5} & <65(0.08) & 0.87(0.92) & 0.57 & 0.57 \\ \mathbf{6} & 116(0.05) & 1.29(0.95) & 0.48 & 0.29 \\ 7 & 122(0.05) & 1.30(0.95) & 0.35 & 0.42 \\ \mathbf{8} & & 1.83(1.0) & 0.19 & 0.35 \\ \mathbf{9} & & 1.82(1.0) & 0.19 & 0.35\end{array}$

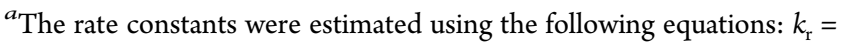
$\phi_{\mathrm{f}} / \tau_{\mathrm{f}}$ and $k_{\mathrm{nr}}=\left(1-\phi_{\mathrm{f}}\right) / \tau_{\mathrm{f}}$, where $\phi_{\mathrm{f}}$ is the measured quantum yield and $\tau_{\mathrm{f}}$ is the fluorescence lifetime. 
Chart 2. Energy Minimized Structure of the Newly Synthesized Chromophores IK-(3-9) ${ }^{a}$
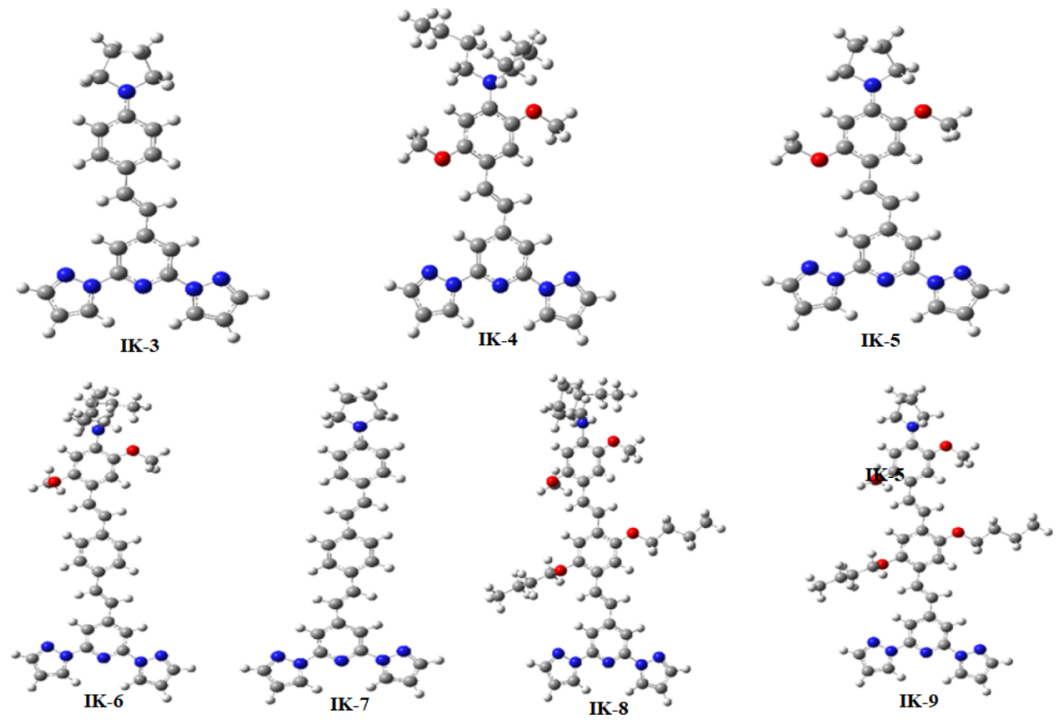

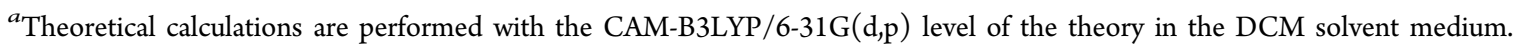

Table 4. Comparison of Energy Values of HOMO (H), LUMO (L), HOMO-LUMO (H-L) gap, [ $\triangle$ HOMO $($ GAS-DCM) = $\Delta \mathrm{H}]$, and $[\Delta \mathrm{LUMO}(\mathrm{GAS}-\mathrm{DCM})=\Delta \mathrm{L}]$ of the Newly Synthesized Chromophores IK-(3-9)

\begin{tabular}{|c|c|c|c|c|c|c|c|c|}
\hline \multirow[b]{2}{*}{ compound IK- } & \multicolumn{3}{|c|}{ gas phase } & \multicolumn{3}{|c|}{ solvent medium (DCM) } & \multirow[b]{2}{*}{$\Delta \mathrm{H}(\mathrm{au})(\mathrm{eV})$} & \multirow[b]{2}{*}{$\Delta \mathrm{L}(\mathrm{au})(\mathrm{eV})$} \\
\hline & $\mathrm{H}(\mathrm{au})$ & $\mathrm{L}(\mathrm{au})$ & $\mathrm{H}-\mathrm{L}(\mathrm{au})(\mathrm{eV})$ & $\mathrm{H}(\mathrm{au})$ & $\mathrm{L}(\mathrm{au})$ & $\mathrm{H}-\mathrm{L}(\mathrm{au})(\mathrm{eV})$ & & \\
\hline 3 & -0.2276 & -0.0134 & $0.2142(5.83)$ & -0.2287 & -0.0214 & $0.2073(5.64)$ & $0.0011(0.029)$ & $0.0079(0.22)$ \\
\hline 4 & -0.2254 & -0.0154 & $0.2101(5.72)$ & -0.2299 & -0.0240 & $0.2059(5.60)$ & $0.0045(0.12)$ & $0.0087(0.23)$ \\
\hline 5 & -0.2162 & -0.0112 & $0.2049(5.58)$ & -0.2198 & -0.0213 & $0.1985(5.40)$ & $0.0036(0.099)$ & $0.0100(0.27)$ \\
\hline 6 & -0.2270 & -0.0318 & $0.1952(5.31)$ & -0.2289 & -0.0365 & $0.1924(5.23)$ & $0.0019(0.051)$ & $0.0048(0.13)$ \\
\hline 7 & -0.2184 & -0.0279 & 0.1905 (5.18) & -0.2205 & -0.0345 & $0.1860(5.06)$ & $0.0021(0.057)$ & $0.0066(0.18)$ \\
\hline 8 & -0.2226 & -0.0293 & $0.1933(5.26)$ & -0.2276 & -0.0360 & $0.1917(5.21)$ & $0.0051(0.137)$ & $0.0067(0.18)$ \\
\hline 9 & -0.2114 & -0.0267 & $0.1847(5.02)$ & -0.2180 & -0.0353 & $0.1826(4.97)$ & $0.0066(0.18)$ & $0.0086(0.23)$ \\
\hline
\end{tabular}

The fastest component can be attributed to the emission originating from the ICT state, and the longest component can be due to the solvent-stabilized ICT state. With the increase in the $\pi$-electron conjugation length and electron-donating ability of the donor counterpart (from IK-3 to IK-9), we could see a progressive increase in the fluorescence lifetime. On the other hand, the same $\pi$-conjugation length but different donating ability for compounds IK-6 and IK-7 or IK-8 and IK-9 do not exhibit any difference in the lifetime. This indicates that the extent of excited-state stabilization for these derivatives is very similar. To understand the effect of solvatochromism and the origin of these decay components, we have recorded the decay traces of compound IK-3 in different solvents, DCM, MeCN, and DMF, as shown in Figure S40 Supporting Information. In the highly nonpolar solvent, such as DCM, we could not be able to fit the decay trace; hence, it is expected to be a lifetime on the order of $<65$ ps. However, with an increase in the medium polarity from $\mathrm{MeCN}$ to $\mathrm{DMF}$, we have observed an increase in the fluorescence lifetime from 0.49 to $0.63 \mathrm{~ns}$ along with the decrease in the nonradiative rate constant for compound IK-3, indicating a stabilization of the excited state in the more polar medium.

Computational Analysis. Energy minimizations of the newly synthesized $\pi$-conjugated chromophores IK-(3-9) are performed in their ground electronic states in the gas phase and also in solvent media (toluene, DCM, MeCN, and DMF). The energy minimized structures of all the title compounds in the DCM solvent are shown in Chart 2.

The optimized structures of the title compounds are treated as the reference points for the time-dependent DFT (TDDFT) calculations. The vertical excitation energy $\left(\lambda_{\max }\right.$ value for absorption) is calculated in the gas phase and in the solvent medium; the relevant data are given in the Supporting Information (Table S9). A uniform increment of $\lambda_{\max }$ value is observed along the series from compounds IK-3 to IK-9 in the gas-phase calculation. This is attributed due to the larger conjugation length between a pair of compounds (IK-3, IK-7) and (IK-4, IK-6). The bathochromic shift between these pairs of compounds is larger in the case of cyclic pyrrolidine substitution $(\sim 47 \mathrm{~nm})$ than the open-chain dibutyl amino substitution $(\sim 15 \mathrm{~nm})$. This indicates that the electrondonating capability of the cyclic pyrrolidine rings is greater than that of the open-chain dibutyl amino donor. The same statement is also applicable during the comparison between compounds IK-8 and IK-9, where both the compounds have same vertical chain length and similar substitution (-OMe and $-\mathrm{OBu})$. A shift of the $\lambda_{\max }$ values for the compounds is observed in the presence of solvents (toluene, DCM, MeCN, and DMF). This is attributed due to the change of energy gap between the HOMO and the LUMO of the compounds in different solvent environments. The energy values of HOMO, LUMO, LUMO-HOMO energy gap, $\triangle \mathrm{HOMO}(\mathrm{GAS}-$ DCM), and $\triangle \mathrm{LUMO}(\mathrm{GAS}-\mathrm{DCM})$ of the compounds, both 

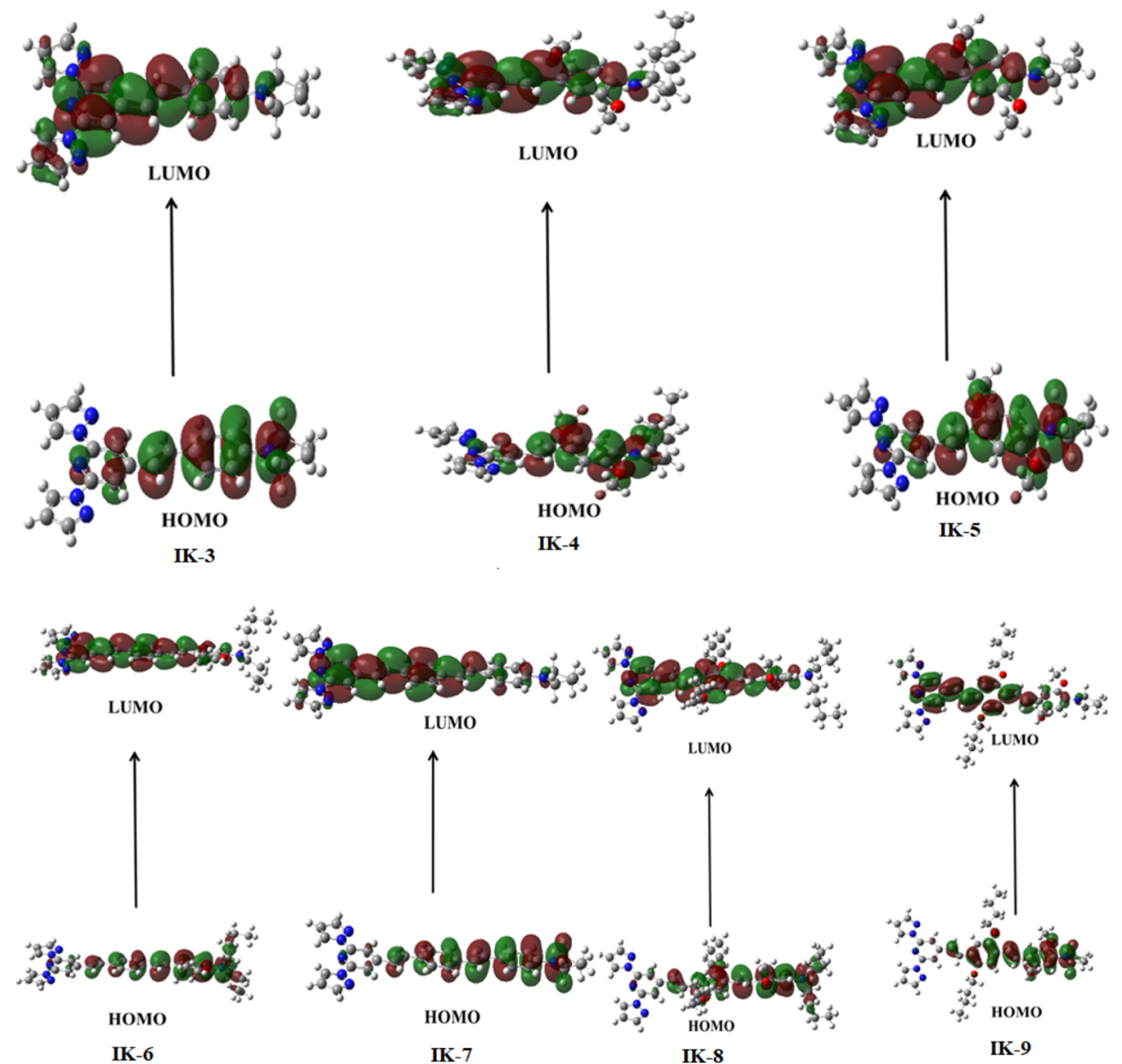

Figure 4. MO diagrams of the energy-minimized structure of the synthesized compounds IK-(3-9).

in the gas phase (GAS) and in the solvent medium (in DCM), are given in Table 4. It is found from the calculations that the LUMO-HOMO energy gap for the title compounds is reduced in the solvent medium compared to that in the gas phase. Both the HOMO and LUMO of the compounds are stabilized in the solvent medium, and the stabilization of LUMO $[\triangle \mathrm{LUMO}(\mathrm{GAS}-\mathrm{DCM})]$ in the solvent medium is greater than that of HOMO $[\Delta \mathrm{HOMO}(\mathrm{GAS}-\mathrm{DCM})]$. As a result, excitation from HOMO to LUMO in each compound becomes easier in the solvent medium. Thus, a bathochromic shift of the absorption spectra is observed from all the compounds in the solvent medium (toluene, DCM, MeCN, and DMF).

The MO diagrams of the HOMO and the LUMO of the energy-minimized structure of the compounds are shown in Figure 4. It is found that the nature of the HOMO of each compound belongs to a $\pi$-bonding type, whereas the same for the LUMO is the $\pi$-antibonding type. The maximum charge density (electron density) of the HOMO is situated at the donor moieties (pyrrolidine or dibutyl amino), and in the case of LUMO, the maximum charge density is situated at the 2,6bis(pyrazolyl)pyridine acceptor moiety. Therefore, the overall $\pi$ $\rightarrow \pi^{*}$ type of electronic transitions in the synthesized compounds occurs from pyrrolidine or dibutyl amino donor moiety to the 2,6-bis(pyrazolyl)pyridine acceptor moiety (charge transfer in the same compound). As a result, this $\pi$ $\rightarrow \pi^{*}$ electronic transition can be called ICT.

Results, given in Table S9 (Supporting Information), indicate that the calculated $\lambda_{\max }$ values using the linear response (LR) model are comparable with the experimental absorption values. An improved set of data of the calculated $\lambda_{\max }$ values are obtained by using the state-specific (SS) model of solvation. The normalized theoretical UV-vis absorption spectra (indicated by solid lines) of the compounds are shown in Figure 5. The solvatochromic shift of the absorption maxima $\left(\lambda_{\max }\right)$ of the compounds was not found prominent, when the absorption was taken place in different solvents: toluene, DCM, $\mathrm{MeCN}$, and DMF by both LR and SS model approaches. For example, the calculated $\lambda_{\max }$ values of compound IK-3 are 368,

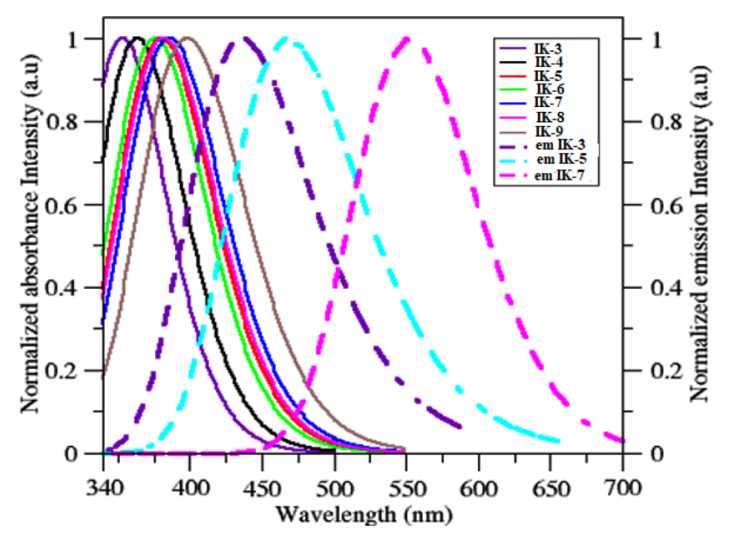

Figure 5. Normalized theoretical absorption spectra (solid lines) of compounds IK-(3-9) and normalized theoretical emission spectra (dashed line) of compounds IK-3, IK-5, and IK-7 in the DCM solvent. 

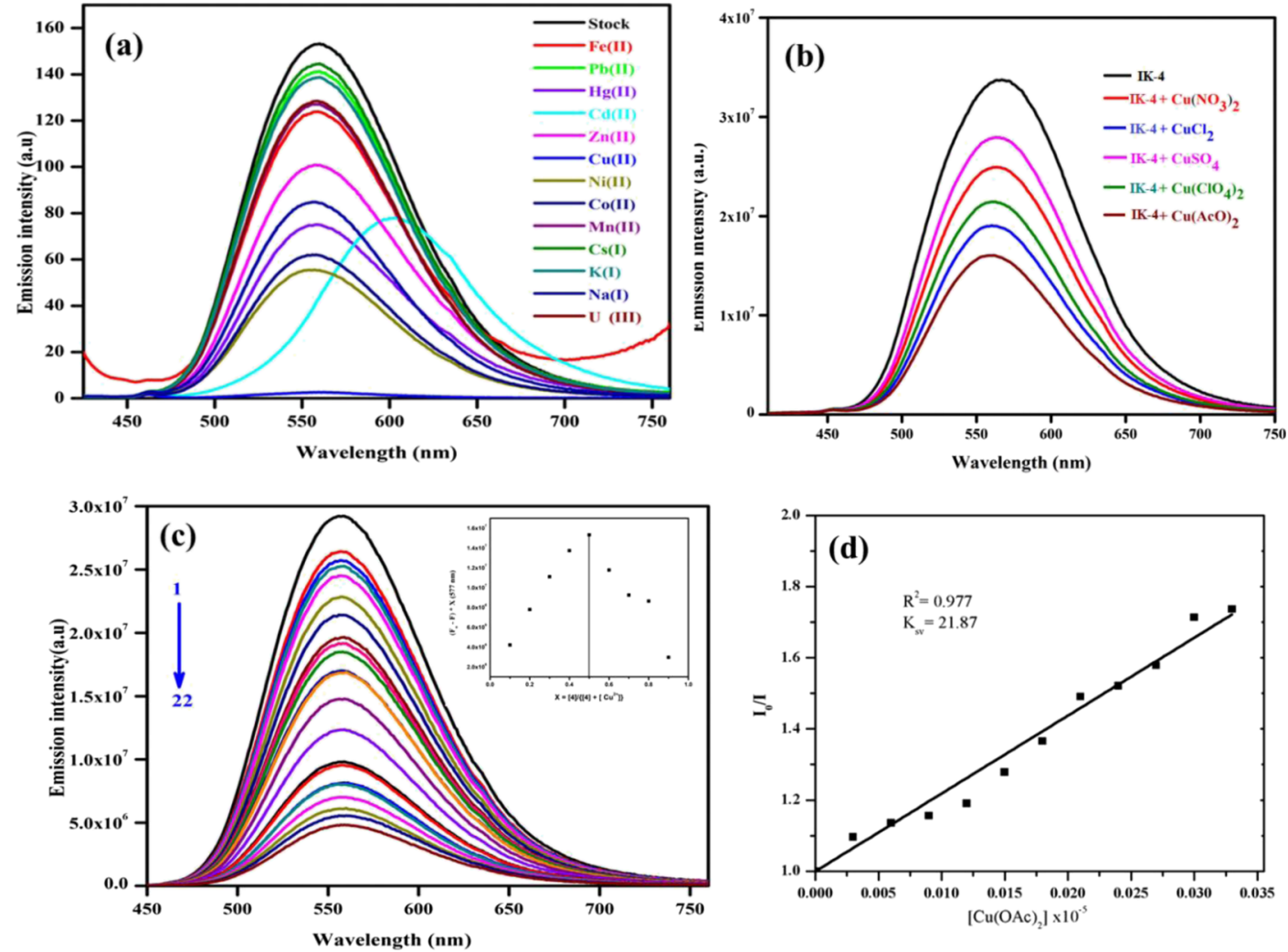

Figure 6. (a) Fluorescence spectra of chromophore IK-4 upon the addition of different cations $\left(\mathrm{M}^{n+}\right)$ in their acetate salts in methanol $\left(\lambda_{\mathrm{ex}}=408\right.$ $\mathrm{nm})$. (b) Emission spectra of IK-4 $(10 \mu \mathrm{M})$ in MeOH in the presence of different copper salts $(10 \mu \mathrm{M})$. (c) Fluorescence titration of chromophore IK-4 in methanol with increasing $\mathrm{Cu}^{2+}$ concentration (adding $1 \mathrm{mM}$ solution of $10 \mu \mathrm{L} \mathrm{Cu}^{2+}$ ions per time; $\lambda_{\mathrm{ex}}=408 \mathrm{~nm}$ ). Job's plot (inset) of IK-4 and $\mathrm{Cu}^{2+}$. (d) Stern-Volmer plot for chromophore IK-4 with $\mathrm{Cu}^{2+}$ (as its acetate salt).

376, 376, and $380 \mathrm{~nm}$ in toluene, DCM, MeCN, and DMF (SS model), respectively. This shows a slight change of absorption maxima for compound IK-3 with the increasing polarity of the solvents. The same results are found for other compounds also, when the calculations are performed in different solvents with increasing polarity. This indicates that the polarity of the solvents has less effect on the absorption spectra of the synthesized compounds.

The overall bathochromic shifts of experimental absorption peaks in compounds IK-3, IK-5, IK-7, and IK-9, with different conjugation lengths and different substitutions, are wellexplained by the TDDFT calculation in different solvent media (toluene, DCM, MeCN, and DMF). The same scenario was observed in the case of compounds IK-4, IK-6, and IK-8. Another observation of the bathochromic shift of absorption peaks is found among the title compounds with the same substitution but different donor moieties (pyrrolidine vs dibutyl amino, see Chart 1) in the solvent medium. An average bathochromic shift of $\sim 16 / 18 \mathrm{~nm}$ and $\sim 18 / 28 \mathrm{~nm}$ (via LR/SS model) is observed for the pair of compounds (IK-4, IK-5) and (IK-8, IK-9), respectively. The results are justified by the LUMO-HOMO energy gap of the compounds (see Table 4). For example, compound IK-9 has less LUMO-HOMO energy gap $(\sim 4.97 \mathrm{eV})$ than compound IK-8 $(\sim 5.21 \mathrm{eV})$. This indicates that the electronic transition from the HOMO $(\pi)$ to the LUMO $\left(\pi^{*}\right)$ is easier in compound IK-9 compared to that in compound IK-8. This observation also concludes that the electron-donating capability of the pyrrolidine donor is greater than that of the dibutyl amino moiety.
The computed fluorescence spectra of compounds IK-3, IK5, and IK-7 in the DCM medium are shown in Figure 5, indicated by the dashed lines. As mentioned in the methodology section, the band structure of the fluorescence spectra is generated by convoluting the stick vibronic lines obtained, from theoretical calculations with the Lorentzian type of function using $0.29 \mathrm{eV}$ full width at half-maxima (fwhm). The intensity of the spectra is normalized to match with the experimental observation. This practice ensures a good comparison between the theoretical and experimental fluorescence spectra. It is noted that theoretically, we calculated only the fluorescence spectra for compounds IK-3, IK-5, and IK-7 in the DCM medium. It is well-known that the evaluation of theoretical fluorescence spectra is computationally very costly, and its cost increased with the size of the molecule. Another difficulty of this calculation is to find out the proper Franck-Condon geometry at the excited state $\left(S_{1}\right)$. For the other compounds, we found this difficulty during calculations. We can able to perform the fluorescence spectral calculation only for compounds IK-3, IK-4, IK-5, and IK-7 in the DCM solvent within the limit of our computational facility. In the case of compound IK-4, we found discrepancies in the Franck-Condon geometry in the excited state. Thus, we get only its $\lambda_{\max }$ value, not its band structure. Theoretically obtained values for $\lambda_{\max }$ in the DCM medium of compounds IK-3, IK-4, IK-5, and IK-7 are $433,460,464$, and $553 \mathrm{~nm}$, respectively. It is found from Figure 5 that bathochromic shifts of the emission maxima (energy gap between $\lambda_{\max }$ ) between the pairs of compounds (IK-3, IK-5) and (IK-5, IK-7) are 31 and $89 \mathrm{~nm}$, respectively. The corresponding values for experimental findings are 51 and 
$63 \mathrm{~nm}$, respectively. This indicates that theoretical data underestimate the change of bathochromic shift in the first pair (IK-3, IK-5) of compounds and overestimate the change of bathochromic shift in the latter pair (IK-5, IK-7) of compounds. However, the same comparison between the pair of compounds IK-3 and IK-7 indicates that the theoretical data $(120 \mathrm{~nm})$ nicely reproduce the experimental observation (114 $\mathrm{nm})$. Therefore, it can be concluded from the above discussion that the change of emission property with the length of the conjugation chain is well-reproduced by theoretical calculations. The overall bathochromic shift of emission maxima from compounds IK-3 to IK-7 is properly explained by this TDDFTbased calculation. It is also noted that the bathochromic shift of emission maxima is more prominent than the same for the absorption maxima when going from compounds IK-3 to IK-9.

Solid-State Emission of the Compounds. Except chromophore IK-7, all other chromophores, IK-(3-6), IK-8, and IK-9, showed a solid-state emission, in addition to the emission in the solution (see Supporting Information, Figure S39). These compounds absorb in the range $400-500 \mathrm{~nm}$, and it is observed that there is a bathochromic shift in the absorption maxima in going from the solution state to the solid state, which signifies the presence of intermolecular interactions between the molecules (might be due to J-aggregation) in the solid state. When these chromophores IK-(3-6), IK-8, and IK9 are excited in their respective absorption maxima (422, 412, $438,470,445$, and $453 \mathrm{~nm}$, respectively), they exhibit emission maxima at 583, 575, 569, 665, 663, and $634 \mathrm{~nm}$, respectively. The spectra of the solution and solid state (except compound IK-7) emission of the title compounds are shown in Figures S36-S39 (Supporting Information).

Highly Selective Turn-Off Phenomenon of a 2,6Bis(pyrazolyl)pyridine-Based Fluorescent Sensor for Recognition of $\mathrm{Cu}^{2+}$. From the series of synthesized chromophores IK-(3-9), we selected IK-4 as a testing probe for the sensing studies. Chromophore IK-4 was chosen for titration experiments because of excellent solubility in the methanol (polar protic) solvent compared to other chromophores, described in this work. Except IK-4, all other chromophores are moderately soluble in the methanol solvent. The titration experiments for the synthesized compound IK-4 were studied with several metal acetates $\left(\mathrm{Na}^{+}, \mathrm{K}^{+}, \mathrm{Mn}^{2+}, \mathrm{Fe}^{2+}\right.$, $\mathrm{Co}^{2+}, \mathrm{Ni}^{2+}, \mathrm{Cu}^{2+}, \mathrm{Zn}^{2+}, \mathrm{Cd}^{2+}, \mathrm{Hg}^{2+}, \mathrm{Pb}^{2+}, \mathrm{Cs}^{+}$, and $\left.\mathrm{U}^{3+}\right)$, commonly found in chemical media. The concentration was maintained as identical for all metal ions in the methanol solvent, which was titrated at an excitation wavelength of 408 $\mathrm{nm}$. The emission data were recorded for $2 \mathrm{~min}$ after a metal acetate solution was added. Indeed, as shown in Figure 6a, drastic quenching in the emission of fluorophore IK-4 demonstrated that $\mathrm{Cu}^{2+}$ alone shows a distinct mark in its fluorescence spectrum (almost labeled with $X$-axis, tiny emission intensity!), which can be observed even by the naked eye. The chelation-enhanced fluorescence quenching (CHEQ) effect may be the reason for this particular quenching response to $\mathrm{Cu}^{2+}$ ions. The paramagnetic (hypothetical) copper(II) coordination complex (a d $\mathrm{d}^{9}$ system) with molecule IK-4 (as a ligand) seems to be responsible for this quenching. ${ }^{47}$ Apart from that, some of other metal ions $\mathrm{M}^{2+}(\mathrm{Ni}, \mathrm{Co}, \mathrm{Hg}$, and $\mathrm{Zn}$ ) and $\mathrm{Na}^{+}$acetate solution also quench the emission to a small extent compared to $\mathrm{Cu}^{2+}$, as shown in Figure 6a. Interestingly, when we added cadmium acetate solution to the solution of fluorophore IK-4, we found that there was a red shift of about $45 \mathrm{~nm}$ (i.e., 559-604 nm), which may be due to the formation of the dimer structure with the cadmium coordination complex.

The UV-vis and fluorescence titration experiments of compound IK-4 with $\mathrm{Cu}^{2+}$ (as its acetate salt) are shown in Figure S4la,b (Supporting Information) with the addition of increasing amount of $\mathrm{Cu}^{2+}$ (as its acetate salt) to a $\mathrm{MeOH}$ solution of compound IK-4. As shown in Figure S41a, the absorbance maximum at $\sim 405 \mathrm{~nm}$ decreases gradually and at the same time, a new absorbance maximum increases at $\sim 480$ $\mathrm{nm}$. A relevant isosbestic point is observed at $\sim 450 \mathrm{~nm}$, clearly indicating the formation of complex between compound IK-4 and $\mathrm{Cu}^{2+}$ (from its acetate salt). Moreover, the effects of anionic counter ions on the sensing behavior of compound IK4 to $\mathrm{Cu}^{2+}$ were also examined. The addition of different contaminants of different copper salts, such as $\mathrm{CuSO}_{4}, \mathrm{CuCl}_{2}$, $\mathrm{Cu}(\mathrm{AcO})_{2}, \mathrm{Cu}\left(\mathrm{ClO}_{4}\right)_{2}$, and $\mathrm{Cu}\left(\mathrm{NO}_{3}\right)_{2}$ to the $\mathrm{MeOH}$ solution of compound IK-4, presents the fluorescence profiles, shown in Figure 6b. As shown in Figure 6b, a negligible effect of different anions on the detection capability of compound IK-4 is realized. As shown from the fluorescence profiles of IK-4 with different counter anions (Figure 6b), the fluorescence quenching is more for $\mathrm{Cu}(\mathrm{AcO})_{2}$ compared to other copper salts. Competitive binding experiment results also indicate that the binding of the $\mathrm{Cu}^{2+}$ ion to IK-4 is much stronger than that of other metal ions (as their acetate salts), as shown in Figure S41c (Supporting Information).

The fluorescence titrations of compound IK-4 were performed by varying the concentrations of $\mathrm{Cu}^{2+}$ ions. The fluorescence intensity of compound IK-4 progressively decreased as $\mathrm{Cu}^{2+}$ (as its acetate salt) was progressively increased. When the amount of $\mathrm{Cu}^{2+}$ added was about $220 \mu \mathrm{M}$, the fluorescence intensity almost reached minimum, as shown in Figure 6c. The relevant Stern-Volmer constant, calculated from the equation $I_{0} / I=1+K_{\mathrm{sv}}[\mathrm{Q}]$, is found to be $K_{\mathrm{sv}}=21.2$ $\mathrm{M}^{-1}$ from the plot, as shown in Figure $6 \mathrm{~d}$. To determine the binding stoichiometry of the IK-4- $\mathrm{Cu}^{2+}$ complex, the Job plot $^{48}$ for the system was performed in the methanol solution by maintaining the total concentration of chromophore IK-4 and $\mathrm{Cu}^{2+}$ at $10 \mu \mathrm{M}$ and changing the molar ratio of $\mathrm{Cu}^{2+}$ $\left(\left[\mathrm{Cu}^{2+}\right] /\left[\mathrm{Cu}^{2+}+\mathrm{IK}-4\right]\right)$ from 0 to 1 , as shown in Figure $6 \mathrm{c}$ (inset). The result shows a maximum at a molar fraction of 0.5 , indicating the formation of $1: 1$ complex of IK-4 and $\mathrm{Cu}^{2+}$. The electrospray ionization mass spectrometry (ESI-MS, Figure S42, Supporting Information) of a mixture of compound IK-4 and $\mathrm{Cu}(\mathrm{OAc})_{2}$ shows the formation of $1: 1$ coordination complex. On the basis of the above studies, an expected binding model for compound IK-4 with $\mathrm{Cu}^{2+}$ is shown in Figure S42 (inset) (Supporting Information).

\section{SUMMARY}

We have described the synthesis and characterization of new conjugated family of 2,6-bis(pyrazolyl)pyridine derivatives with phenyl substituted donor $-\pi$-acceptor molecules (Chart 1 ). Precursor compound IK-2 and the first member of the series (compound IK-3) are additionally characterized by the singlecrystal X-ray structure determination. The title compounds IK(3-9) represent a unique family in the sense that this series contains a common 2,6-bis(pyrazolyl)pyridine unit acting as an acceptor moiety, common to each member of the family and diverse donor functionalities. Chromophores IK-(3-9) are characterized by an ICT from the donors to the acceptor moiety. We have demonstrated that the described compounds show large solvent sensitive emissive behavior and their 
photophysical properties are highly dependent on the number, nature, and position of the donor functionalities, which have also been corroborated computationally by TDDFT calculations. We have demonstrated that fluorescence spectra of chromophores IK-3, IK-5, and IK-7 can be explained by density functional calculations. At the last, we have shown that molecule IK-4 can be described as a selective molecular sensor for the recognition of $\mathrm{Cu}^{2+}$ ion; we have demonstrated this by fluorescence experiments of compound IK-4 with a series of metal ions (as acetates). Among all metal acetates, we took, only copper acetate quenches the fluorescence extensively. We have also performed fluorescence lifetime studies, which indicate that the stabilization of the excited state is more in the polar medium.

\section{EXPERIMENTAL, PHYSICAL, AND THEORETICAL METHODS}

Physical Measurements. All reagents and solvents were commercially available and used without purification. All reactions were carried out under inert atmosphere unless otherwise stated. Column chromatography was performed on a silica gel (100-200 mesh). Thin-layer chromatography (TLC) plates were visualized with UV light in an iodine chamber. Unless stated otherwise, all reagents were purchased from commercial sources and used without additional purification. Tetrahydrofuran (THF) was freshly distilled over $\mathrm{Na}$ benzophenone ketyl. ${ }^{1} \mathrm{H}$ NMR and ${ }^{13} \mathrm{C}$ NMR spectra were recorded on a Bruker $400 \mathrm{MHz}$ machine in $\mathrm{CDCl}_{3}$ as a solvent with tetramethylsilane as a reference unless otherwise indicated. Microanalytical (C, H, and $\mathrm{N}$ ) data were obtained with a FLASH EA 1112 Series CHNS analyzer. IR spectra were recorded as $\mathrm{KBr}$ pellets on a JASCO-5300 Fourier transform infrared spectrophotometer at $298 \mathrm{~K}$. A high-resolution mass spectroscopy (HRMS) (ESI-TOF) equipment was used to record mass spectra for isolated compounds where appropriate. Absorbance spectra were recorded on a Shimadzu model UV3600 spectrophotometer, and fluorescence emission spectra have been recorded on a Jobin Yvon HORIBA model FluoroMax-4 spectrofluorometer. Time-resolved fluorescence decay measurements were performed using a time-correlated single photon counting setup (HORIBA Jobin Yvon IBH). Diode laser $(375 \mathrm{~nm})$ and an MCP photomultiplier (Hamamatsu R3809U-50) were used as an excitation source and the detector, respectively. The lamp profile, which determines the instrumental resolution $(\sim 65 \mathrm{ps})$, was recorded using a Ludox scatterer. Fluorescence decay curves were analyzed using IBH DAS6 (version 2.2) decay analysis software.

Synthesis of Diethyl((2,6-di(1H-pyrazol-1-yl)pyridin-4yl)methyl)phosphonate (IK-2). In the presence of nitrogen atmosphere, $0.30 \mathrm{~g}$ ( $1 \mathrm{mmol})$ of compound IK-1 was dissolved in $5 \mathrm{~mL}$ of dry triethyl phosphate. It was then refluxed for $24 \mathrm{~h}$ at $130{ }^{\circ} \mathrm{C}$. The reaction mixture was cooled to room temperature, whereby the white solid was separated from the solution mixture. The precipitate was washed with petroleum ether and dried in vacuum. This crude product was recrystallized by vapor diffusion of petroleum ether into a DCM solution of the crude product. After 1 week, colorless needleshaped crystals of compound IK-2 were deposited in the bottom of a glass vial, which was inside the conical flask. Compound IK-2 crystallizes in the $P \overline{1}$ space group belonging to the triclinic crystal system (see Figure $1 \mathrm{a}$ and Table 1). Yield: $0.19 \mathrm{~g}(52 \%)$. Anal. Calcd for $\mathrm{C}_{16} \mathrm{H}_{20} \mathrm{~N}_{5} \mathrm{O}_{3} \mathrm{P}: \mathrm{C}, 53.18 ; \mathrm{H}, 5.58$; $\mathrm{N}, 19.38$. Found: C, 53.25; H, 5.62; N, 19.28. IR (KBr pellet) $\nu$ $\left(\mathrm{cm}^{-1}\right)$ for IK-2: 3159m, 3122s, 2986w, 2947s, 2918m, 1787m, $1724 \mathrm{w}, 1269 \mathrm{~m}(>\mathrm{P}=\mathrm{O})$; $1153 \mathrm{~m}, 1020 \mathrm{w}, 867 \mathrm{~m}(>\mathrm{P}-\mathrm{O}-\mathrm{C})$; $758 \mathrm{~m} .{ }^{1} \mathrm{H}$ NMR $\left(400 \mathrm{MHz}, \mathrm{CDCl}_{3}\right): \delta 8.56(\mathrm{~d}, J=2 \mathrm{~Hz}, 2 \mathrm{H})$, 7.83 (d, $J=2 \mathrm{~Hz}, 2 \mathrm{H}), 7.73$ (d, $J=1 \mathrm{~Hz}, 2 \mathrm{H}), 6.50$ (d, $J=2$ $\mathrm{Hz}, 2 \mathrm{H}), 4.16-4.10$ (m, 4H), 3.29 (d, $J=23 \mathrm{~Hz}, 2 \mathrm{H}), 1.32$ (t, $J$ $=7 \mathrm{~Hz}, 6 \mathrm{H}) .{ }^{13} \mathrm{C} \mathrm{NMR}\left(100 \mathrm{MHz}, \mathrm{CDCl}_{3}\right): \delta 150.2,147.4$, 147.3, 142.4 (2C), 127.1 (2C), 110.6, 110.5, 108.0 (2C), 62.6, $62.5,34.6-33.5,16.4,16.4$. HRMS $(\mathrm{m} / z)$ : calcd for $\mathrm{C}_{16} \mathrm{H}_{20} \mathrm{~N}_{5} \mathrm{O}_{3} \mathrm{P}, 361.1304\left(\mathrm{M}^{+}\right)$; found, $362.1381(\mathrm{M}+\mathrm{H})^{+}$.

Synthesis of $(E)-2,6-\mathrm{Di}(1 \mathrm{H}$-pyrazol-1-yl)-4-(4-(pyrrolidin-1-yl)styryl)pyridine (IK-3). Solid potassium tert-butoxide $(0.17 \mathrm{~g}, 1.5 \mathrm{mmol})$ was added to a THF solution $(40 \mathrm{~mL})$ of the dpp-phosphonate (IK-2, $0.36 \mathrm{~g}, 1 \mathrm{mmol}$ ) and 4-(pyrrolidin1-yl)benzaldehyde $\left(S_{1 c}, 0.17 \mathrm{~g}, 1 \mathrm{mmol}\right.$; see Scheme $\mathrm{S} 1$, Supporting Information, for structural representation of $S_{1 c}$ ) under nitrogen atmosphere at room temperature. The resulting heterogeneous reaction mixture was stirred for $2 \mathrm{~h}$. The reaction mixture was subsequently quenched with water (15 $\mathrm{mL}$ ), and the product was extracted with DCM. The resulting mixture was washed several times with water and then with sodium chloride solution (brine). It was then purified on a silica gel (100-200 mesh) column using ethyl acetate/hexane 5:95 $\mathrm{v} / \mathrm{v}$ as the eluent to obtain compound IK-3 as a yellow-colored solid. This crude product was crystallized by vapor diffusion of diethyl ether into a DCM solution of the crude product. After 1 week, needle-shaped crystals were isolated as yellow crystals, which crystallize in the $P 2_{1} / c$ space group (vide infra). Yield: $0.27 \mathrm{~g}$ (71\%). Anal. Calcd for $\mathrm{C}_{23} \mathrm{H}_{22} \mathrm{~N}_{6}: \mathrm{C}, 72.23 ; \mathrm{H}, 5.80 ; \mathrm{N}$, 21.97. Found: C, 72.35; H, 5.72; N, 21.82. IR (KBr pellet) $\nu$ $\left(\mathrm{cm}^{-1}\right)$ for IK-3: 2957s, 1598w, 1386m, 1200s, 1030w, $921 \mathrm{~s}$. ${ }^{1} \mathrm{H}$ NMR (400 MHz, $\mathrm{CDCl}_{3}$ ): $\delta 8.61(\mathrm{~d}, J=2 \mathrm{~Hz}, 2 \mathrm{H}), 7.93$ (s, $2 \mathrm{H}), 7.80(\mathrm{~s}, 2 \mathrm{H}), 7.52-7.47(\mathrm{~m}, 3 \mathrm{H}), 6.94(\mathrm{~d}, J=16 \mathrm{~Hz}, 1 \mathrm{H})$, 6.59 (d, $J=8 \mathrm{~Hz}, 2 \mathrm{H}), 6.52(\mathrm{~d}, J=2 \mathrm{~Hz}, 2 \mathrm{H}), 3.37(\mathrm{t}, J=6 \mathrm{~Hz}$, $4 \mathrm{H}), 2.05(\mathrm{t}, J=6 \mathrm{~Hz}, 4 \mathrm{H}) .{ }^{13} \mathrm{C} \mathrm{NMR}\left(100 \mathrm{MHz} \mathrm{CDCl}_{3}\right): \delta$ $151.8,150.4,148.5,142.1,135.4,128.8,127.2,123.1,111.8$, 107.7, 105.9, 47.6, 25.5. HRMS $(m / z)$ : calcd for $\mathrm{C}_{23} \mathrm{H}_{22} \mathrm{~N}_{6}$, $382.1906\left(\mathrm{M}^{+}\right)$; found, $383.1986(\mathrm{M}+\mathrm{H})^{+}$.

Synthesis of (E)-N,N-Dibutyl-4-(2-(2,6-di(1H-pyrazol-1yl)pyridin-4-yl)vinyl)-2,5-dimethoxyaniline (IK-4). Dppphosphonate (IK-2, $0.36 \mathrm{~g}, 1 \mathrm{mmol})$ and aldehyde $S_{2 \mathrm{c}}(0.29$ g, $1 \mathrm{mmol}$; see Scheme S1, Supporting Information, for structural representation of $S_{2 c}$ ) were dissolved in $15 \mathrm{~mL}$ of dry THF. Then, potassium tert-butoxide $(0.17,1.5 \mathrm{mmol})$ was added to the reaction mixture at $0{ }^{\circ} \mathrm{C}$ (ice bath) under nitrogen atmosphere; the ice bath was then removed, and the reaction mixture was allowed to stir at room temperature for $1 \mathrm{~h}$. Then, the resulting dark red color solution was quenched with $10 \mathrm{~mL}$ of water, and the product was extracted with DCM. The organic layer was washed several times with water and brine and dried over $\mathrm{Na}_{2} \mathrm{SO}_{4}$, and the crude product was purified by column chromatography using a silica gel (100-200 mesh) using ethyl acetate/hexane $5: 95 \mathrm{v} / \mathrm{v}$ as the eluent to obtain compound IK-4, which is an orange color solid. Yield: $0.34 \mathrm{~g}$ (69\%). Anal. Calcd for $\mathrm{C}_{29} \mathrm{H}_{36} \mathrm{~N}_{6} \mathrm{O}_{2}: \mathrm{C}, 69.57 ; \mathrm{H}, 7.25 ; \mathrm{N}$, 16.79. Found: C, 69.45; H, 7.15; N, 16.86. IR (KBr pellet) $\nu$ $\left(\mathrm{cm}^{-1}\right)$ for IK-4: 2952s, 2855w, 1591w, 1280s, 1102m, 1044s. ${ }^{1} \mathrm{H}$ NMR (400 MHz, $\left.\mathrm{CDCl}_{3}\right): \delta 8.58(\mathrm{~m}, 3 \mathrm{H}), 7.94(\mathrm{~s}, 2 \mathrm{H})$, $7.79(\mathrm{~d}, J=14 \mathrm{~Hz}, 2 \mathrm{H}), 7.07$ (d, $J=18 \mathrm{~Hz}, 2 \mathrm{H}), 6.49(\mathrm{~m}, 2 \mathrm{H})$, $6.47(\mathrm{~s}, 1 \mathrm{H}), 3.87(\mathrm{~s}, 3 \mathrm{H}), 3.86(\mathrm{~s}, 3 \mathrm{H}), 3.19(\mathrm{t}, J=7 \mathrm{~Hz}, 4 \mathrm{H})$, $1.54-1.47(\mathrm{~m}, 4 \mathrm{H}), 1.30$ (sextet, $4 \mathrm{H}), 0.91(\mathrm{t}, J=7 \mathrm{~Hz}, 6 \mathrm{H})$. ${ }^{13} \mathrm{C}$ NMR (100 MHz, $\left.\mathrm{CDCl}_{3}\right): \delta 152.9,151.9,150.5(2 \mathrm{C})$, $146.8,142.7,142.1$ (2C), 129.9, 127.2 (2C), 122.9, 116.7, 
111.3, 107.7 (2C), 106.2 (2C), 104.1, 56.3, 56.1, 52.2 (2C), $29.5(2 \mathrm{C}), 20.5(2 \mathrm{C}), 14.0(2 \mathrm{C})$. HRMS $(\mathrm{m} / z)$ : calcd for $\mathrm{C}_{29} \mathrm{H}_{36} \mathrm{~N}_{6} \mathrm{O}_{2}, 500.2900\left(\mathrm{M}^{+}\right)$; found, $501.2979(\mathrm{M}+\mathrm{H})^{+}$.

Synthesis of (E)-4-(2,5-Dimethoxy-4-(pyrrolidin-1-yl)styryl)-2,6-di(1H-pyrazol-1-yl)pyridine (IK-5). Dpp-phosphonate (IK-2, $0.36 \mathrm{~g}, 1 \mathrm{mmol})$ and aldehyde $S_{3 \mathrm{c}}(0.23 \mathrm{~g}, 1$ mmol; see Scheme S1, Supporting Information, for structural representation of $S_{3 c}$ ) were taken in $15 \mathrm{~mL}$ of dry THF. Then, potassium tert-butoxide $(0.17,1.5 \mathrm{mmol})$ was added to the reaction mixture at $0{ }^{\circ} \mathrm{C}$ (ice bath) under nitrogen atmosphere; the ice bath was then taken out, and the reaction mixture was allowed to stir at room temperature for $1 \mathrm{~h}$. Then, the resulting dark red color solution was quenched with $10 \mathrm{~mL}$ of water, and the product was extracted with DCM. The organic layer was washed several times with water and brine and dried over $\mathrm{Na}_{2} \mathrm{SO}_{4}$, and the crude product was purified by column chromatography using a silica gel (100-200 mesh) using ethyl acetate/hexane 5:95 v/v as the eluent to obtain compound IK5 as a brown-colored solid. Yield: $0.33 \mathrm{~g}(76 \%)$. Anal. Calcd for $\mathrm{C}_{25} \mathrm{H}_{26} \mathrm{~N}_{6} \mathrm{O}_{2}$ : C, 67.85; H, 5.92; N, 18.99. Found: C, 67.73; H, 5.98; N, 18.82. IR ( $\mathrm{KBr}$ pellet) $\nu\left(\mathrm{cm}^{-1}\right)$ for IK-5: $2958 \mathrm{w}$, $1598 \mathrm{w}, 1396 \mathrm{~m}, 1200 \mathrm{~s}, 1107 \mathrm{w}, 957 \mathrm{~s} .{ }^{1} \mathrm{H}$ NMR $(400 \mathrm{MHz}$, $\left.\mathrm{CDCl}_{3}\right): \delta 8.59(\mathrm{~s}, 2 \mathrm{H}), 7.93(\mathrm{~s}, 2 \mathrm{H}), 7.79(\mathrm{~d}, J=14 \mathrm{~Hz}, 3 \mathrm{H})$, $7.06(\mathrm{~s}, 1 \mathrm{H}), 7.01(\mathrm{~d}, J=17 \mathrm{~Hz}, 1 \mathrm{H}), 6.50(\mathrm{~d}, J=1 \mathrm{~Hz}, 2 \mathrm{H})$, $6.24(\mathrm{~s}, 1 \mathrm{H}), 3.88(\mathrm{~s}, 3 \mathrm{H}), 3.82(\mathrm{~s}, 3 \mathrm{H}), 3.44(\mathrm{br}, 4 \mathrm{H}), 1.95$ (br, $4 \mathrm{H}) .{ }^{13} \mathrm{C}$ NMR $\left(100 \mathrm{MHz}, \mathrm{CDCl}_{3}\right): \delta 153.7,152.2,150.4$ (2C), 143.6, 142.0 (2C), 130.1, 127.2 (2C), 127.0, 121.4, 111.9, 109.2, 107.6 (2C), 106.0 (2C), 98.8, 56.9, 56.0, 50.4 (2C), 25.2 (2C). HRMS $(m / z)$ : calcd for $\mathrm{C}_{25} \mathrm{H}_{26} \mathrm{~N}_{6} \mathrm{O}_{2}, 442.2117\left(\mathrm{M}^{+}\right)$; found, $443.2198(\mathrm{M}+\mathrm{H})^{+}$.

Synthesis of $N, N$-Dibutyl-4-((E)-4-((E)-2-(2,6-di(1H-pyrazol-1-yl)pyridin-4-yl)vinyl)styryl)-2,5-dimethoxyaniline (IK-6). Dpp-phosphonate (IK-2, $0.36 \mathrm{~g}, 1 \mathrm{mmol}$ ) and aldehyde $S_{4 c}(0.60 \mathrm{~g}, 1 \mathrm{mmol}$; see Scheme S1, Supporting Information, for structural representation of $S_{4 \mathrm{c}}$ ) were dissolved in $15 \mathrm{~mL}$ of dry THF. Potassium tert-butoxide $(0.17,1.5 \mathrm{mmol})$ was then added to the reaction mixture at $0{ }^{\circ} \mathrm{C}$ (ice bath) in an inert atmosphere; the ice bath was then removed, and the reaction mixture was allowed to stir at room temperature for $1 \mathrm{~h}$. Then, the resulting dark red color solution was quenched with $10 \mathrm{~mL}$ of water, and the product was extracted with the DCM solvent. The organic layer was washed several times with water and brine and dried over $\mathrm{Na}_{2} \mathrm{SO}_{4}$, and the crude product was purified by column chromatography using a silica gel (100-200 mesh) using ethyl acetate/hexane $5: 95 \mathrm{v} / \mathrm{v}$ as the eluent to obtain compound IK-6 as a dark red color solid. Yield: $0.48 \mathrm{~g}$ (80\%). IR (KBr pellet) $\nu_{\max }: 2956 \mathrm{w}, 2915 \mathrm{~s}, 1727 \mathrm{w}, 1582 \mathrm{~s}$, $1510 \mathrm{~m}, 1453 \mathrm{~s}, 1386 \mathrm{~m}, 1205 \mathrm{~s}, 1102 \mathrm{~m}, 952 \mathrm{w} .{ }^{1} \mathrm{H}$ NMR (400 $\left.\mathrm{MHz}, \mathrm{CDCl}_{3}\right): \delta 8.56(\mathrm{~s}, 2 \mathrm{H}), 7.94(\mathrm{~s}, 2 \mathrm{H}), 7.78(\mathrm{~s}, 2 \mathrm{H}), 7.55-$ $7.46(\mathrm{~m}, 6 \mathrm{H}), 7.12-7.02(\mathrm{~m}, 2 \mathrm{H}), 6.98(\mathrm{~d}, J=16 \mathrm{~Hz}, 1 \mathrm{H})$, $6.51(\mathrm{~s}, 1 \mathrm{H}), 6.50(\mathrm{br}, 2 \mathrm{H}), 3.87(\mathrm{~s}, 3 \mathrm{H}), 3.85(\mathrm{~s}, 3 \mathrm{H}), 3.16(\mathrm{t}, J$ $=8 \mathrm{~Hz}, 2 \mathrm{H}), 1.54-1.46(\mathrm{~m}, 4 \mathrm{H}), 1.31($ sextet, $4 \mathrm{H}), 0.91(\mathrm{t}, J=$ $7 \mathrm{~Hz}, 6 \mathrm{H}) .{ }^{13} \mathrm{C} \mathrm{NMR}\left(100 \mathrm{MHz}, \mathrm{CDCl}_{3}\right): \delta 151.9,150.7,150.5$ (2C), 147.4, 142.2 (2C), 141.4, 139.4, 134.4, 134.3, 127.5 (2C), 127.2 (2C), 126.6 (2C), 125.5, 124.5, 124.2, 118.6, 110.3, 107.87, 106.4 (2C), 105.1, 56.4, 56.3, 52.3 (2C), $29.3(2 \mathrm{C})$, $20.5(2 \mathrm{C}), 14.0(2 \mathrm{C})$. HRMS $(\mathrm{m} / z)$ : calcd for $\mathrm{C}_{37} \mathrm{H}_{42} \mathrm{~N}_{6} \mathrm{O}_{2}$, $602.3369\left(\mathrm{M}^{+}\right)$; found, $603.3448(\mathrm{M}+\mathrm{H})^{+}$. Anal. Calcd for $\mathrm{C}_{37} \mathrm{H}_{42} \mathrm{~N}_{6} \mathrm{O}_{2}:$ C, 73.73; $\mathrm{H}, 7.02 ; \mathrm{N}, 13.94$. Found: $\mathrm{C}, 73.65 ; \mathrm{H}$, 7.14; N, 14.04 .

Synthesis of 2,6-Di(1H-pyrazol-1-yl)-4-((E)-4-((E)-4(pyrrolidin-1-yl)styryl)styryl)pyridine (IK-7). Dpp-phosphonate $(\mathrm{IK}-2,0.36 \mathrm{~g}, 1 \mathrm{mmol})$ and aldehyde $S_{5 \mathrm{c}}(0.277 \mathrm{~g}, 1$ mmol; see Scheme S1, Supporting Information, for structural representation of $S_{5 c}$ ) were dissolved in $15 \mathrm{~mL}$ of dry THF. Then, potassium tert-butoxide $(0.17,1.5 \mathrm{mmol})$ was added to the reaction mixture at $0{ }^{\circ} \mathrm{C}$ (ice bath) under nitrogen atmosphere; the ice bath was then removed, and the reaction mixture was allowed to stir at room temperature for $1 \mathrm{~h}$. Then, the resulting dark gray color solution was quenched with $10 \mathrm{~mL}$ of water, and the product was extracted with the DCM solvent. The organic layer was washed several times with water and brine and dried over $\mathrm{Na}_{2} \mathrm{SO}_{4}$, and the crude product was purified by column chromatography using a silica gel (100-200 mesh) using ethyl acetate/hexane $5: 95 \mathrm{v} / \mathrm{v}$ as the eluent to obtain compound IK-7, which was isolated as a gray microcrystalline solid. Yield: $0.32 \mathrm{~g}$ (67\%). IR ( $\mathrm{KBr}$ pellet) $\nu_{\max }: 2920 \mathrm{w}, 2853 \mathrm{~s}, 1732 \mathrm{~s}, 1608 \mathrm{~m}, 1551 \mathrm{w}, 1458 \mathrm{~s}, 1396 \mathrm{~m}$, $1210 \mathrm{w}, 1045 \mathrm{~s}, 957 \mathrm{~m}, 864 \mathrm{~s} .{ }^{1} \mathrm{H} \mathrm{NMR}\left(400 \mathrm{MHz} \mathrm{CDCl}_{3}\right): \delta$ $8.61(\mathrm{~d}, J=2 \mathrm{~Hz}, 2 \mathrm{H}), 7.98(\mathrm{~s}, 2 \mathrm{H}), 7.81(\mathrm{~d}, J=1 \mathrm{~Hz}, 2 \mathrm{H})$, 7.55 (s, 1H), 7.53 (d, $J=3 \mathrm{~Hz}, 3 \mathrm{H}), 7.51(\mathrm{~s}, 1 \mathrm{H}), 7.44$ (d, $J=8$ $\mathrm{Hz}, 2 \mathrm{H}), 7.14(\mathrm{~d}, J=16 \mathrm{~Hz}, 1 \mathrm{H}), 7.13(\mathrm{~d}, J=16 \mathrm{~Hz}, 1 \mathrm{H}), 6.91$ $(\mathrm{d}, J=16 \mathrm{~Hz}, 1 \mathrm{H}), 6.59(\mathrm{~s}, 1 \mathrm{H}), 6.57(\mathrm{~s}, 1 \mathrm{H}), 6.54-6.53(\mathrm{br}$, $2 \mathrm{H}), 3.35(\mathrm{t}, J=6 \mathrm{~Hz}, 4 \mathrm{H}), 2.04(\mathrm{t}, J=6 \mathrm{~Hz}, 4 \mathrm{H}) .{ }^{13} \mathrm{C} \mathrm{NMR}$ $\left(100 \mathrm{MHz}_{\mathrm{CDCl}}\right): \delta 150.8,150.5$ (2C), 147.7, $142.3(2 \mathrm{C})$, 139.4, 134.6, 133.9, 130.9, 127.9 (2C), 127.6 (2C), 127.2 (2C), 126.3 (2C), 124.5, 124.3, 122.8, 111.8 (2C), 107.9 (2C), 106.4 (2C), $47.6(2 \mathrm{C}), 25.5(2 \mathrm{C})$. HRMS $(\mathrm{m} / z)$ : calcd for $\mathrm{C}_{31} \mathrm{H}_{28} \mathrm{~N}_{6}$, 484.2375 $\left(\mathrm{M}^{+}\right)$; found, $485.2456(\mathrm{M}+\mathrm{H})^{+}$. Anal. Calcd for $\mathrm{C}_{31} \mathrm{H}_{28} \mathrm{~N}_{6}$ : C, 76.83; H, 5.82; N, 17.34. Found: C, 76.93; H, 5.75; N, 17.25 .

Synthesis of $N, N$-Dibutyl-4-((E)-2,5-dibutoxy-4-((E)-2(2,6-di(1H-pyrazol-1-yl)pyridin-4-yl)vinyl)styryl)-2,5-dimethoxyaniline (IK-8). Dpp-phosphonate (IK-2, 0.36 g, 1 $\mathrm{mmol})$ and aldehyde $\mathrm{S}_{6 \mathrm{c}}(0.53 \mathrm{~g}, 1 \mathrm{mmol}$; see Scheme $\mathrm{S} 1$, Supporting Information, for structural representation of $\mathbf{S}_{\mathbf{6 c}}$ ) were dissolved in $15 \mathrm{~mL}$ of dry THF. Then, potassium tertbutoxide $(0.17,1.5 \mathrm{mmol})$ was added to the reaction mixture at $0{ }^{\circ} \mathrm{C}$ (ice bath) under nitrogen atmosphere; the ice bath was then removed, and the reaction mixture was allowed to stir at room temperature for $1 \mathrm{~h}$. Then, the resulting dark red color solution was quenched with $10 \mathrm{~mL}$ of water, and the product was extracted with DCM. The organic layer was washed several times with water and brine and dried over $\mathrm{Na}_{2} \mathrm{SO}_{4}$, and the crude product was purified by column chromatography using a silica gel (100-200 mesh) using ethyl acetate/hexane 5:95 v/v as the eluent to obtain compound IK-8 as a dark brown solid. Yield: $0.51 \mathrm{~g}$ (69\%). IR (KBr pellet) $\nu_{\max }: 2956 \mathrm{w}, 2930 \mathrm{~s}, 2863 \mathrm{~s}$, $1726 \mathrm{w}, 1582 \mathrm{~m}, 1515 \mathrm{~s}, 1468 \mathrm{w}, 1344 \mathrm{~s}, 1199 \mathrm{~s}, 1106 \mathrm{~m}, 1034 \mathrm{~s}$, 957m, 853m. ${ }^{1} \mathrm{H}$ NMR (400 MHz, $\left.\mathrm{CDCl}_{3}\right) ; 8.61(\mathrm{~d}, J=2 \mathrm{~Hz}$, 2H), 7.99 (s, $2 \mathrm{H}), 7.80(\mathrm{~d}, J=1 \mathrm{~Hz}, 3 \mathrm{H}), 8.08$ (d, $J=16 \mathrm{~Hz}$, $1 \mathrm{H}), 7.37$ (d, $J=16 \mathrm{~Hz}, 1 \mathrm{H}), 7.27(\mathrm{~d}, J=16 \mathrm{~Hz}, 1 \mathrm{H}), 7.18(\mathrm{~s}$, $1 \mathrm{H}), 7.15(\mathrm{~s}, 1 \mathrm{H}), 7.11(\mathrm{~s}, 1 \mathrm{H}), 6.53-6.52(\mathrm{br}, 3 \mathrm{H}), 4.13(\mathrm{t}, J=$ $7 \mathrm{~Hz}, 2 \mathrm{H}), 4.07(\mathrm{t}, J=6 \mathrm{~Hz}, 2 \mathrm{H}), 3.88(\mathrm{~d}, J=5 \mathrm{~Hz}, 6 \mathrm{H}), 3.17$ $(\mathrm{t}, J=7 \mathrm{~Hz}, 4 \mathrm{H}), 1.92-1.86(\mathrm{~m}, 4 \mathrm{H}), 1.66-1.60(\mathrm{~m}, 4 \mathrm{H}), 1.52$ $(\mathrm{t}, J=7 \mathrm{~Hz}, 4 \mathrm{H}), 1.35-1.30(\mathrm{~m}, 4 \mathrm{H}), 1.09-1.04(\mathrm{~m}, 6 \mathrm{H}), 0.93$ $(\mathrm{t}, J=7 \mathrm{~Hz}, 6 \mathrm{H}) .{ }^{13} \mathrm{C} \mathrm{NMR}\left(100 \mathrm{MHz}, \mathrm{CDCl}_{3}\right): \delta 152.0(2 \mathrm{C})$, $151.9,151.6,150.8,150.6$ (2C), 147.6, 142.2 (2C), 141.2, $130.3,129.8,127.2$ (2C), 125.5, 124.3, 121.0, 119.6, 112.0, $110.6,110.5,107.8$ (2C), 106.5 (2C), 105.5, 69.3 (2C), 56.6, 56.3, 52.4 (2C), 31.6, 31.5, 29.4 (2C), 20.5, 19.5 (2C). HRMS $(\mathrm{m} / z)$ : calcd for $\mathrm{C}_{45} \mathrm{H}_{58} \mathrm{~N}_{6} \mathrm{O}_{4}, 746.4520\left(\mathrm{M}^{+}\right)$; found, 747.4599 $(\mathrm{M}+\mathrm{H})^{+}$. Anal. Calcd for $\mathrm{C}_{45} \mathrm{H}_{58} \mathrm{~N}_{6} \mathrm{O}_{4}: \mathrm{C}, 72.36 ; \mathrm{H}, 7.83$; N, 11.25. Found: C, 72.45; H, 7.76; N, 11.36 .

Synthesis of 4-((E)-2,5-Dibutoxy-4-((E)-2,5-dimethoxy4-(pyrrolidin-1-yl)styryl)styryl)-2,6-di(1H-pyrazol-1-yl)- 
pyridine (IK-9). Dpp-phosphonate (IK-2, $0.36 \mathrm{~g}, 1 \mathrm{mmol}$ ) and aldehyde $S_{7 \mathrm{c}}(0.48 \mathrm{~g}, 1.0 \mathrm{mmol}$; see Scheme S1, Supporting Information, for structural representation of $S_{7 c}$ ) were dissolved in $15 \mathrm{~mL}$ of dry THF. Then, potassium tert-butoxide $(0.17 \mathrm{~g}$, $1.5 \mathrm{mmol}$ ) was added to the reaction mixture at $0{ }^{\circ} \mathrm{C}$ (ice bath) under nitrogen atmosphere; the ice bath was then removed, and the reaction mixture was allowed to stir at room temperature for $1 \mathrm{~h}$. Then, the resulting dark red color solution was quenched with $10 \mathrm{~mL}$ of water, and the product was extracted with DCM. The organic layer was washed several times with water and brine and dried over $\mathrm{Na}_{2} \mathrm{SO}_{4}$, and the crude product was purified by column chromatography using a silica gel (100-200 mesh) using ethyl acetate/hexane 5:95 v/v as the eluent to obtain compound IK-9 was isolated as a dark red gum. Yield: $0.49 \mathrm{~g}(71 \%)$. IR (neat) $\nu_{\max }$ : 2954.6, 2923.5, 2853.9, 1734.4, 1588.6, 1504.7, 1463.2, 1376.7, 1202.4, 1042.1, 968.1, 853.3. ${ }^{1} \mathrm{H}$ NMR (400 MHz, $\left.\mathrm{CDCl}_{3}\right) ; 8.61(\mathrm{~d}, J=1 \mathrm{~Hz}$, $1 \mathrm{H}), 8.61(\mathrm{~d}, J=1 \mathrm{~Hz}, 1 \mathrm{H}), 7.99(\mathrm{~s}, 2 \mathrm{H}), 7.81(\mathrm{~d}, J=16 \mathrm{~Hz}$, $1 \mathrm{H}), 7.80(\mathrm{~d}, J=1 \mathrm{~Hz}, 2 \mathrm{H}) 7.50(\mathrm{~d}, J=16 \mathrm{~Hz}, 1 \mathrm{H}), 7.31$ (d, $J$ $=16 \mathrm{~Hz}, 1 \mathrm{H}), 7.26(\mathrm{~d}, J=16 \mathrm{~Hz}, 1 \mathrm{H}), 7.17(\mathrm{~d}, J=16 \mathrm{~Hz}, 2 \mathrm{H})$, $7.10(\mathrm{~s}, 1 \mathrm{H}), 6.52\left(\mathrm{dd}, J_{1}=3 \mathrm{~Hz}, J_{2}=2 \mathrm{~Hz}, 2 \mathrm{H}\right), 6.32(\mathrm{~s}, 1 \mathrm{H})$, $4.14(\mathrm{t}, J=7 \mathrm{~Hz}, 2 \mathrm{H}), 4.07(\mathrm{t}, J=6 \mathrm{~Hz}, 2 \mathrm{H}), 3.89(\mathrm{~s}, 3 \mathrm{H}), 3.86$ (s, $3 \mathrm{H}), 3.43(\mathrm{br}, 4 \mathrm{H}), 1.98(\mathrm{t}, J=7 \mathrm{~Hz}, 4 \mathrm{H}), 1.96-1.87(\mathrm{~m}$, $4 \mathrm{H}), 1.66-1.60(\mathrm{~m}, 4 \mathrm{H}), 1.08(\mathrm{t}, J=7 \mathrm{~Hz}, 3 \mathrm{H}), 1.05(\mathrm{t}, J=7$ $\mathrm{Hz}, 3 \mathrm{H}) .{ }^{13} \mathrm{C}$ NMR $\left(100 \mathrm{MHz}, \mathrm{CDCl}_{3}\right): \delta 152.5,152.1,151.6$, $150.54,150.5$ (2C), 144.2, 142.2 (2C), 140.9, 130.4, 130.0, 127.2 (2C), 125.3, 124.4, 123.9, 119.4, 116.4, 120.0, 110.8, 110.0, 107.8 (2C), 106.5 (2C), 99.7, 69.2, 69.2, 56.8, 56.5, 50.5 (2C), 31.6, 31.5, 25.1 (2C), 19.5 (2C), 14.03, 14.01. HRMS $(\mathrm{m} / z)$ : calcd for $\mathrm{C}_{41} \mathrm{H}_{48} \mathrm{~N}_{6} \mathrm{O}_{4}, 688.3737\left(\mathrm{M}^{+}\right)$; found, 688.3795 $\left(\mathrm{M}^{+}\right)$. Anal. Calcd for $\mathrm{C}_{41} \mathrm{H}_{48} \mathrm{~N}_{6} \mathrm{O}_{4}$ : C, 71.49; H, 7.02; N, 12.02 . Found: C, 71.32; H, 7.08; N, 12.36.

X-ray Crystallography. Single crystals, suitable for facile structural determination for compounds IK-2 and IK-3, were measured on a Bruker D8 QUEST PHOTON 100 CMOS system under Mo $\mathrm{K} \alpha(\lambda=0.71073 \AA)$ graphite monochromatic X-ray beam. Data processing was accomplished by using SAINT-Plus, and structures were solved by using SHELXS-97 and refined using SHELXL-14/7 program. ${ }^{49}$ All nonhydrogen atoms were refined anisotropically by full-matrix least-square cycles on $F^{2}$. Hydrogen atoms were introduced on calculated positions and included in the refinement riding on their respective parent atoms. Detailed information about crystal data and structure for compounds IK-2 and IK-3 is summarized in Table 1. CCDC 1564452 and CCDC 1564457 contain the supplementary crystallographic data of compounds IK-2 and IK-3, respectively. Relevant crystal data can be obtained free of charge via http://www.ccdc.cam.atc.uk/conts/retrieving.html or from the Cambridge Crystallographic Data Centre, 12 Union Road, Cambridge CB2 1EZ, UK; fax: $(+44) 1223-336-$ 033; or e-mail: deposit@ccdc.cam.ac.uk.

Computational Methods. Energy minimization calculations of the ground electronic state $\left(S_{o}\right)$ of different chromophores IK-(3-9) were performed with DFT employing CAM-B3LYP hybrid functional and 6-31G(d,p) basis set of Pople, using Gaussian 09 program modules. ${ }^{50}$ The energy minima of the compounds were confirmed by the subsequent frequency analysis with the same level of theory. The solvent effect of the title chromophores (compounds IK-(3-9)) has been accounted by placing the compounds in the solvent cavity by following the self-consistent reaction field approach as implemented in Gaussian 09 program modules. ${ }^{50}$ The polarizable continuum model (PCM) approach was imple- mented to create the solvent cavity. ${ }^{51}$ The selected solvents are toluene, DCM, MeCN, and DMF. The vertical excitation energy of the excited states of the chromophores was calculated with the TDDFT using same functional and basis set by Gaussian 09 program modules. ${ }^{51}$ The vertical $S_{0} \rightarrow S_{1}$ transition energies were computed taking the ground energy minimized structure as a reference. The geometry of the $S_{1}$ state of the compounds was calculated by analytic TDDFT gradients implemented in Gaussian 09 suite program. ${ }^{52,53}$ The frequency analysis of the $S_{1}$ state of the compounds was subsequently determined by numerical variation of the TDDFT gradients. This allows us to confirm the absence of imaginary frequencies and to compute the different thermodynamic data.

The vertical excitation energies from $S_{0} \rightarrow S_{1}$ transition for each compound were computed considering the solvent reaction field in both by the $\mathrm{LR}^{54}$ and SS model. ${ }^{55}$ The polarization of the solvent cavity in the presence of solute (compounds IK-(3-9)) is considered in the SS model. Therefore, the accuracy of the SS model is greater than that of the LR approach at the price of significant increase of the computational cost. The properties of the excited states (mainly fluorescence transition) were calculated within the limits of both equilibrium (eq) and nonequilibrium (neq) schemes of solvation under modified PCM. In the eq scheme, the solvent molecules reorient themselves according to the polarization of the electronic distribution of the solute. However, in the neq scheme, solvent molecules find no time to reorient themselves according to the electronic distribution of the excited states of solute. Thus, the eq scheme needs higher computational cost than the neq scheme. Geometry optimization in the ground and excited states follows the eq scheme, whereas the vertical transitions (absorption or emission) follow the neq scheme. Overall, the emission spectrum is calculated following the principle discussed in refs $^{56-58}$ and references therein. The emission spectra of the compounds IK-3, IK-5, and IK-7 were calculated by visualizing the following representation (Scheme 1).

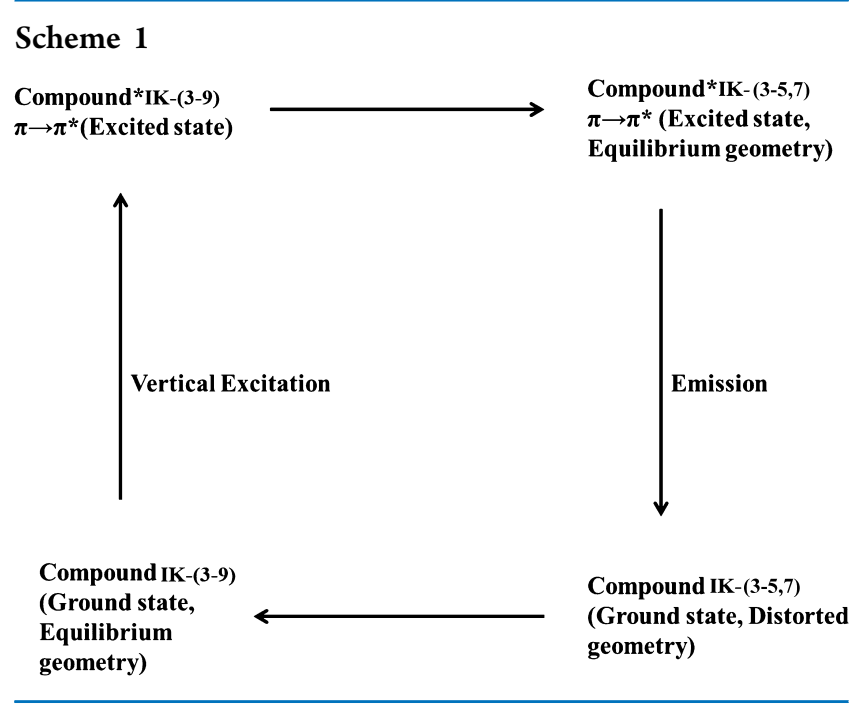

The calculation of the fluorescence band structure of the compounds was obtained by convoluting the stick lines (vide infra) with the following Lorentzian line shape function with $\Gamma$ fwhm to reproduce the experimental resolution. 


$$
L(E)=\frac{1}{\pi} \frac{\frac{\Gamma}{2}}{E^{2}+\left(\frac{\Gamma}{2}\right)^{2}}
$$

\section{ASSOCIATED CONTENT}

\section{(S) Supporting Information}

The Supporting Information is available free of charge on the ACS Publications website at DOI: 10.1021/acsomega.7b02006.

X-ray crystallographic data of IK-2 and CCDC 1564452 (IK-2) (CIF)

X-ray crystallographic data of IK-3 and CCDC 1564457 (IK-3) (CIF)

Synthetic routes of donor and acceptor molecules, crystal parameters, bond length, and bond angle tables of compounds IK-2 and IK-3; ${ }^{1} \mathrm{H}$ NMR, ${ }^{13} \mathrm{C}$ NMR, HRMS spectra, and $\mathrm{CHN}$ analysis plot, UV-vis and emission spectra of compounds IK-(3-9); and fluorescence decay plot of compound IK-3 in DCM, MeCN, and DMF solutions and tables related to computational data (PDF)

\section{AUTHOR INFORMATION}

\section{Corresponding Author}

*E-mail: skdas@uohyd.ac.in. Phone: +91-40-2313-4853 (S.K.D.).

\section{ORCID}

Rudraditya Sarkar: 0000-0001-7915-8625

Navendu Mondal: 0000-0001-5002-9678

Samar K. Das: 0000-0002-9536-6579

\section{Notes}

The authors declare no competing financial interest.

\section{ACKNOWLEDGMENTS}

We thank SERB, DST, Government of India, for financial support (project no. SB/S1/IC-34/2013). We are grateful to UGC, New Delhi, for UPE-II grant. Our special thanks to Professor Anunay Samanta, School of Chemistry, University of Hyderabad, for his help in arranging fluorescence lifetime studies and relevant discussions. Professor Susanta Mahapatra, School of Chemistry, University of Hyderabad, is gratefully acknowledged for his kind cooperation in theoretical calculations along with helpful discussions. We are also thankful to DST PURSE, UPE-II, and UGC-SAP phase III.

\section{REFERENCES}

(1) Herschel, J. F. W. On a Case of Superficial Colour Presented by a Homogeneous Liquid Internally Colourless. Philos. Trans. R. Soc. London 1845, 135, 143-145.

(2) Lakowicz, J. R. Principles of Fluorescence Spectroscopy, 3rd ed.; Springer Sciences and Business Media: New York, 2006.

(3) Wolfbeis, O. S. Springer Series on Fluorescence: Methods and Applications; Springer Sciences and Business Media: Berlin, Heidelberg, 2010.

(4) Lakowicz, J. R. Topics in Fluorescence Spectroscopy; Kluwer Academic Publishers: New York, 2002; Vol. 1-4.

(5) Meier, H. Conjugated oligomers with terminal donor-acceptor substitution. Angew. Chem., Int. Ed. Engl. 2005, 44, 2482-2506.

(6) Abbotto, A.; Beverina, L.; Bozio, R.; Facchetti, A.; Ferrante, C.; Pagani, G. A.; Pedron, D.; Signorini, R. Novel heteroaromatic-based multi-branched dyes with enhanced two-photon absorption activity. Chem. Commun. 2003, 2144-2145.

(7) Mazzucato, S.; Fortunati, I.; Scolaro, S.; Zerbetto, M.; Ferrante, C.; Signorini, R.; Pedron, D.; Bozio, R; Locatelli, D.; Righetto, S.;
Roberto, D.; Ugo, R.; Abbotto, A.; Archetti, G.; Beverina, L.; Ghezzi, S. Two-photon absorption of $\mathrm{Zn}(\mathrm{II})$ octupolar molecules. Phys. Chem. Chem. Phys. 2007, 9, 2999-3005.

(8) Grabowski, Z. R.; Rotkiewicz, K.; Rettig, W. Structural Changes Accompanying Intramolecular Electron Transfer: Focus on Twisted Intramolecular Charge-Transfer States and Structures. Chem. Rev. 2003, 103, 3899-4032.

(9) Glasbeek, M.; Zhang, H. Femtosecond Studies of Solvation and Intramolecular Configurational Dynamics of Fluorophores in Liquid Solution. Chem. Rev. 2004, 104, 1929-1954.

(10) Soujanya, T.; Philippon, A.; Leroy, S.; Vallier, M.; Fages, F. Tunable Photophysical Properties of Two 2,2'-Bipyridine-Substituted Pyrene Derivatives. J. Phys. Chem. A 2000, 104, 9408-9414.

(11) Slama-Schwok, A.; Blanchard-Desce, M.; Lehn, J. M. Intramolecular charge transfer in donor-acceptor molecules. J. Phys. Chem. 1990, 94, 3894-3902.

(12) Takaya, T.; Saha, S.; Hamaguchi, H.-o.; Sarkar, M.; Samanta, A.; Iwata, K. Charge Resonance Character in the Charge Transfer State of Bianthryls: Effect of Symmetry Breaking on Time-Resolved Near-IR Absorption Spectra. J. Phys. Chem. A 2006, 110, 4291-4295.

(13) Mondal, J. A.; Sarkar, M.; Samanta, A.; Ghosh, H. N.; Palit, D. K. Charge-Transfer-Induced Twisting of the Nitro Group. J. Phys. Chem. A 2007, 111, 6122-6126.

(14) Felouat, A.; D’Aléo, A.; Charaf-Eddin, A.; Jacquemin, D.; Le Guennic, B.; Kim, E.; Lee, K. J.; Woo, J. H.; Ribierre, J.-C.; Wu, J. W.; Fages, F. Tuning the Direction of Intramolecular Charge Transfer and the Nature of the Fluorescent State in a T-Shaped Molecular Dyad. J. Phys. Chem. A 2015, 119, 6283-6295.

(15) Horng, M. L.; Gardecki, J. A.; Papazyan, A.; Maroncelli, M. Subpicosecond Measurements of Polar Solvation Dynamics: Coumarin 153 Revisited. J. Phys. Chem. 1995, 99, 17311-17337.

(16) Bagchi, B.; Fleming, G. R.; Oxtoby, D. W. Theory of electronic relaxation in solution in the absence of an activation barrier. J. Chem. Phys. 1983, 78, 7375-7385.

(17) Videlot-Ackermann, C.; Brisset, H.; Zhang, J.; Ackermann, J.; Nénon, S.; Fages, F.; Marsal, P.; Tanisawa, T.; Yoshimoto, N. Influence of Phenyl Perfluorination on Charge Transport Properties of Distyryl-Oligothiophenes in Organic Field-Effect Transistors. J. Phys. Chem. C 2009, 113, 1567-1574.

(18) Curtis, M. D.; Cao, J.; Kampf, J. W. Solid-State Packing of Conjugated Oligomers: From $\pi$-Stacks to the Herringbone Structure. J. Am. Chem. Soc. 2004, 126, 4318-4328.

(19) Chen, S. Y.; Xu, X. J.; Liu, Y. Q.; Yu, G.; Sun, X. B.; Qiu, W. F.; Ma, Y. Q.; Zhu, D. B. Synthesis and Characterization of n-Type Materials for Non-Doped Organic Red-Light-Emitting Diodes. Adv. Funct. Mater. 2005, 15, 1541-1546.

(20) Lai, R. Y.; Fabrizio, E. F.; Lu, L.; Jenekhe, S. A.; Bard, A. J. Synthesis, Cyclic Voltammetric Studies, and Electrogenerated Chemiluminescence of a New Donor Acceptor Molecule: 3,7-[Bis[4phenyl-2-quinolyl]]-10-methylphenothiazine. J. Am. Chem. Soc. 2001, 123, 9112-9118.

(21) Wong, M. S.; Li, Z. H.; Tao, Y.; D’Iorio, M. Synthesis and Functional Properties of Donor-Acceptor $\pi$-Conjugated Oligomers. Chem. Mater. 2003, 15, 1198-1203.

(22) Jiao, G.-S.; Thoresen, L. H.; Burgess, K. Fluorescent, ThroughBond Energy Transfer Cassettes for Labeling Multiple Biological Molecules in One Experiment. J. Am. Chem. Soc. 2003, 125, 1466814669.

(23) Sreejith, S.; Divya, K. P.; Ajayaghosh, A. Detection of zinc ions under aqueous conditions using chirality assisted solid-state fluorescence of a bipyridyl based fluorophore. Chem. Commun. 2008, 2903-2905.

(24) Ajayaghosh, A.; Carol, P.; Sreejith, S. A Ratiometric Fluorescence Probe for Selective Visual Sensing of $\mathrm{Zn}^{2+}$. J. Am. Chem. Soc. 2005, 127, 14962-14963.

(25) Divya, K. P.; Sreejith, S.; Balakrishna, B.; Jayamurthy, P.; Anees, P.; Ajayaghosh, A. A $\mathrm{Zn}^{2+}$-specific fluorescent molecular probe for the selective detection of endogenous cyanide in biorelevant samples. Chem. Commun. 2010, 46, 6069-6071. 
(26) Sarma, M.; Chatterjee, T.; Ghanta, S.; Das, S. K. D- $\pi$-A-A- $\pi$-D Prototype 2,2'-Bipyridine Dyads Exhibiting Large Structure and Environment-Sensitive Fluorescence: Synthesis, Photophysics, and Computation. J. Org. Chem. 2012, 77, 432-444.

(27) Bodapati, R.; Sarma, M.; Kanakati, A.; Das, S. K. Asymmetrically Substituted and $\pi$-Conjugated 2,2'-Bipyridine Derivatives: Synthesis, Spectroscopy, Computation, and Crystallography. J. Org. Chem. 2015, 80, 12482-12491.

(28) Supriya, S.; Das, S. K. Reversible Single Crystal to Single Crystal Transformation through $\mathrm{Fe}-\mathrm{O}(\mathrm{H}) \mathrm{Me} / \mathrm{Fe}-\mathrm{OH}_{2}$ Bond Formation/ Bond Breaking in a Gas-Solid Reaction at an Ambient Condition. J. Am. Chem. Soc. 2007, 129, 3464-3465.

(29) Supriya, S.; Das, S. K. Solid-to-solid formation at the solid-liquid interface leading to a chiral coordination polymer from an achiral monomer. Chem. Commun. 2011, 47, 2062-2064.

(30) Madhu, V.; Sabbani, S.; Kishore, R.; Naik, I. K.; Das, S. K. Mechanical motion in the solid state and molecular recognition: reversible cis-trans transformation of an organic receptor in a solidliquid crystalline state reaction triggered by anion exchange. CrystEngComm 2015, 17, 3219-3223.

(31) Kumar, G.; Guda, R.; Husain, A.; Bodapati, R.; Das, S. K. A Functional $\mathrm{Zn}(\mathrm{II})$ Metallacycle Formed from an N-Heterocyclic Carbene Precursor: A Molecular Sensor for Selective Recognition of $\mathrm{Fe}^{3+}$ and $\mathrm{IO}_{4}^{-}$Ions. Inorg. Chem. 2017, 56, 5017-5025.

(32) Boal, A. K.; Rosenzweig, A. C. Structural Biology of Copper Trafficking. Chem. Rev. 2009, 109, 4760-4779.

(33) Davis, A. V.; O'Halloran, T. V. A place for thioether chemistry in cellular copper ion recognition and trafficking. Nat. Chem. Biol. 2008, $4,148-151$.

(34) Kim, B.-E.; Nevitt, T.; Thiele, D. J. Mechanisms for copper acquisition, distribution and regulation. J. Nat. Chem. Biol. 2008, 4, $176-185$.

(35) Bergonzi, R.; Fabbrizzi, L.; Licchelli, M.; Mangano, C. Molecular switches of fluorescence operating through metal centred redox couples. Coord. Chem. Rev. 1998, 170, 31-46.

(36) Gonzáles, A. P. S.; Firmino, M. A.; Nomura, C. S.; Rocha, F. R. P.; Oliveira, P. V.; Gaubeur, I. Peat as a natural solid-phase for copper preconcentration and determination in a multicommuted flow system coupled to flame atomic absorption spectrometry. Anal. Chim. Acta 2009, 636, 198-204.

(37) Becker, J. S.; Zoriy, M. V.; Pickhardt, C.; Palomero-Gallagher, N.; Zilles, K. Imaging of Copper, Zinc, and Other Elements in Thin Section of Human Brain Samples (Hippocampus) by Laser Ablation Inductively Coupled Plasma Mass Spectrometry. Anal. Chem. 2005, 77, 3208-3216.

(38) Liu, Y.; Liang, P.; Guo, L. Nanometer titanium dioxide immobilized on silica gel as sorbent for preconcentration of metal ions prior to their determination by inductively coupled plasma atomic emission spectrometry. Talanta 2005, 68, 25-30.

(39) Pathirathna, P.; Yang, Y.; Forzley, K.; McElmurry, S. P.; Hashemi, P. Fast-Scan Deposition-Stripping Voltammetry at CarbonFiber Microelectrodes: Real-Time, Subsecond, Mercury Free Measurements of Copper. Anal. Chem. 2012, 84, 6298-6302.

(40) Umehara, K.; Kuwata, S.; Ikariya, T. N-N Bond Cleavage of Hydrazines with a Multiproton-Responsive Pincer-Type Iron Complex. J. Am. Chem. Soc. 2013, 135, 6754-6757.

(41) Deng, H.; Yu, Z.; Dong, J.; Wu, S. 2,6-Bis(3,5-dimethylpyrazol1-yl)pyridine: A Useful Pseudo- $\mathrm{N}_{3}$ Ligand in Efficient Ruthenium(II)Catalyzed Transfer Hydrogenation of Ketones. Organometallics 2005, 24, 4110-4112.

(42) Zhu, X. J.; Holliday, B. J. Electropolymerization of a Ruthenium(II) Bis(pyrazolyl)pyridine Complex to Form a Novel Ru-Containing Conducting Metallopolymer. J. Macromol. Rapid Commun. 2010, 31, 904-909.

(43) Jameson, D. L.; Goldsby, K. A. 2,6-Bis(N-pyrazolyl)pyridines: The Convenient Synthesis of a Family of Planar Tridentate N3 Ligands That Are Terpyridine Analogues. J. Org. Chem. 1990, 55, 4992-4994.
(44) Ganesan, S.; Muthuraaman, B.; Madhavan, J.; Mathew, V.; Maruthamuthu, P.; Suthanthiraraj, S. A. The use of 2,6-bis (Npyrazolyl)pyridine as an efficient dopant in conjugation with poly(ethylene oxide) for nanocrystalline dye-sensitized solar cells. Electrochim. Acta 2008, 53, 7903-7907.

(45) Schäfer, B.; Greisch, J.-F.; Faus, I.; Bodenstein, T.; Šalitroš, I.; Fuhr, O.; Fink, K.; Schünemann, V.; Kappes, M. M.; Ruben, M. Divergent Coordination Chemistry: Parallel Synthesis of $[2 \times 2]$ Iron(II) Grid-Complex Tauto-Conformers. Angew. Chem., Int. Ed. 2016, 55, 10881-10885.

(46) Nihei, M.; Takahashi, N.; Nishikawa, H.; Oshio, H. Spincrossover behavior and electrical conduction property in iron(ii) complexes with tetrathiafulvalene moieties. Dalton Trans. 2011, 40, 2154-2156.

(47) Varnes, A. W.; Dodson, R. B.; Wehry, E. L. Interactions of transition-metal ions with photoexcited states of flavines. Fluorescence quenching studies. J. Am. Chem. Soc. 1972, 94, 946-950.

(48) Hu, Y.; Ke, Q.; Yan, C.; Xu, C.-H.; Huang, X.-H.; Hu, S.-l. A new fluorescence chemosensor for selective detection of copper ion in aqueous solution. Tetrahedron Lett. 2016, 57, 2239-2243.

(49) Sheldrick, G. M. SHELX-97, Program for Crystal Structure Solution and Analysis; University of Gottingen: Gottingen, Germany, 1997.

(50) Frisch, M. J.; Trucks, G. W.; Schlegel, H. B.; Scuseria, G. E.; Robb, M. A.; Cheeseman, J. R.; Scalmani, G.; Barone, V.; Mennucci, B.; Petersson, G. A.; et al. Gaussian 09, revision B.01; Gaussian, Inc.: Wallingford, CT, 2010.

(51) Tomasi, J.; Mennucci, B.; Cammi, R. Quantum Mechanical Continuum Solvation Models. Chem. Rev. 2005, 105, 2999-3094.

(52) Furche, F.; Ahlrichs, R. Adiabatic time-dependent density functional methods for excited state properties. J. Chem. Phys. 2002, $117,7433-7447$.

(53) Scalmani, G.; Frisch, M. J.; Mennucci, B.; Tomasi, J.; Cammi, R.; Barone, V. Geometries and properties of excited states in the gas phase and in solution: Theory and application of a time-dependent density functional theory polarizable continuum model. J. Chem. Phys. 2006, 124, 094107.

(54) Cossi, M.; Barone, V. Time-dependent density functional theory for molecules in liquid solutions. J. Chem. Phys. 2001, 115, 4708-4717.

(55) Improta, R.; Barone, V.; Santoro, F. Ab Initio Calculations of Absorption Spectra of Large Molecules in Solution: Coumarin C153. Angew. Chem., Int. Ed. 2007, 46, 405-408.

(56) Adamo, C.; Jacquemin, D. The calculations of excited-state properties with Time-Dependent Density Functional Theory. Chem. Soc. Rev. 2013, 42, 845-856.

(57) Krawczyk, P. Time-dependent density functional theory calculations of the solvatochromism of some azo sulfonamide fluorochromes. J. Mol. Model. 2015, 21, 1-18.

(58) Chibani, S.; Le Guennic, B.; Charaf-Eddin, A.; Maury, O.; Andraud, C.; Jacquemin, D. On the Computation of Adiabatic Energies in Aza-Boron-Dipyrromethene Dyes. J. Chem. Theory Comput. 2012, 8, 3303-3313. 